\title{
Diabetes and Kidney Disease: Role of Oxidative Stress
}

\author{
Jay C. Jha, Claudine Banal, Bryna S.M. Chow, Mark E. Cooper, ${ }^{1,2}$ and Karin Jandeleit-Dahm,2
}

\begin{abstract}
Significance: Intrarenal oxidative stress plays a critical role in the initiation and progression of diabetic kidney disease (DKD). Enhanced oxidative stress results from overproduction of reactive oxygen species (ROS) in the context of concomitant, insufficient antioxidant pathways. Renal ROS production in diabetes is predominantly mediated by various NADPH oxidases (NOXs), but a defective antioxidant system as well as mitochondrial dysfunction may also contribute. Recent Advances: Effective agents targeting the source of ROS generation hold the promise to rescue the kidney from oxidative damage and prevent subsequent progression of DKD. Critical Issues and Future Directions: In the present review, we summarize and critically analyze molecular and cellular mechanisms that have been demonstrated to be involved in NOX-induced renal injury in diabetes, with particular focus on the role of increased glomerular injury, the development of albuminuria, and tubulointerstitial fibrosis, as well as mitochondrial dysfunction. Furthermore, novel agents targeting NOX isoforms are discussed. Antioxid. Redox Signal. 25, 657-684.
\end{abstract}

Keywords: reactive oxygen species, NADPH-oxidases, diabetic nephropathy, albuminuria

\section{Introduction}

D IABETES IS INCREASINGLY recognized as the leading cause of chronic renal failure, with many patients progressing to end-stage renal disease (ESRD) and requiring dialysis or transplantation (178). Diabetic kidney disease (DKD), also referred to as diabetic nephropathy (DN), is clinically characterized by a progressive increase in albuminuria and a subsequent decline in the glomerular filtration rate. This disorder is often accompanied by a disproportionate decrease in afferent arteriole resistance, while there is an increase in efferent arteriole resistance, with the resulting intraglomerular hypertension causing further damage to the kidney, and ultimately leading to end-stage renal failure $(45,50)$. The pathogenesis and clinical manifestations of DKD usually follow a predetermined course that is associated with marked structural changes in the kidney, including renal hypertrophy, enlargement of glomerular capillaries, mesangial expansion, and glomerular basement membrane (GBM) thickening due to excessive deposition of extracellular matrix (ECM) (131). The development and progression of DKD are complex processes due to the wide diversity of cell populations present within the kidney and the various physiological roles of this organ (216).
Chronic hyperglycemia leads to the activation of several pathological processes, which affect numerous resident renal cells, including the glomerular endothelial cells, smooth muscle cells, mesangial cells, podocytes, and cells of the tubular and collecting ducts (83) (Fig. 1). Accumulating evidence has now implicated these key renal cell types in driving the structural and functional changes in diabetic kidneys (131). Possessing a crucial role in maintaining normal glomerular capillary permeability, endothelial cells and podocytes become structurally immature with diminution of the endothelial glycocalyx in hyperglycemic conditions (224). Of importance, ultraglomerular structural changes, including changes in podocyte structure and function, are closely related to an increase in albuminuria in DKD (123). In addition, with mesangial cells constituting the central position in the renal glomerulus, they are increasingly recognized to be primary contributors to renal fibrosis due to excessive accumulation of ECM proteins (collagen IV and fibronectin), with this eventually leading to glomerulosclerosis. Structural and functional changes of key glomerular cells also adversely affect tubular cells, ultimately leading to accelerated tubulointerstitial fibrosis $(32,168,257)$. Several mechanisms have been implicated in the underlying detrimental effects of hyperglycemia-induced tissue damage.

\footnotetext{
${ }^{1}$ Diabetic Complications Division, JDRF Danielle Alberti Memorial Centre for Diabetic Complications, Baker IDI Heart and Diabetes Institute, Melbourne, Australia.

${ }^{2}$ Department of Medicine, Monash University, Melbourne, Australia.
} 


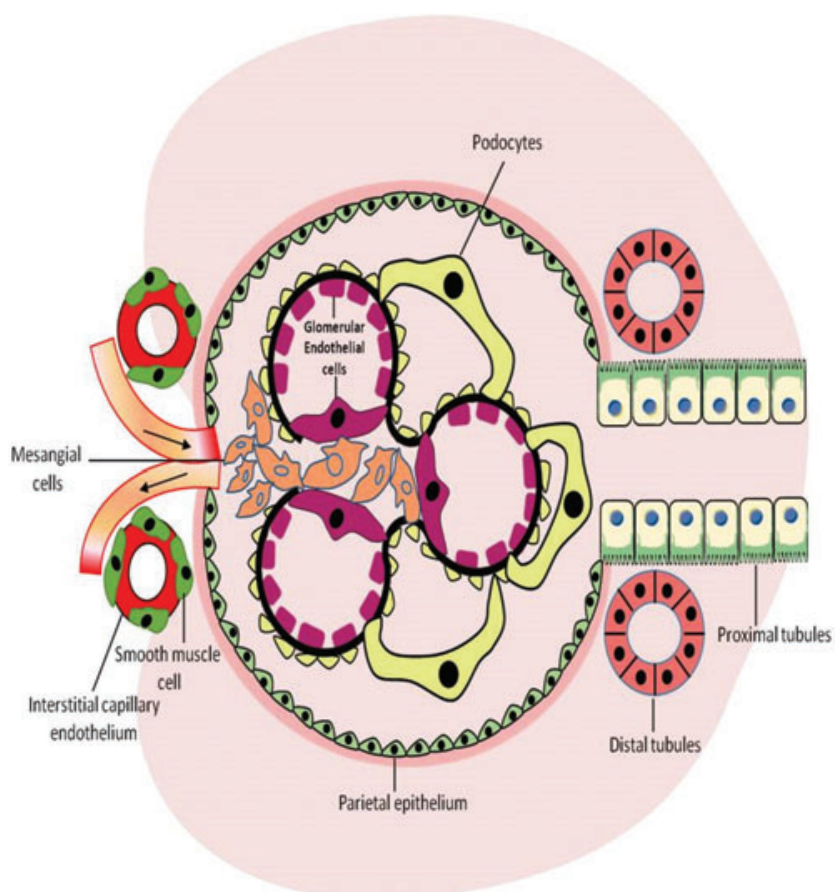

FIG. 1. Involvement of resident renal cells in pathogenesis of DKD. DKD, diabetic kidney disease. To see this illustration in color, the reader is referred to the web version of this article at www.liebertpub.com/ars

Activation of the renin-angiotensin-aldosterone system (RAAS), polyol- and advanced glycation end product (AGE)dependent pathways, the hexosamine pathway flux, activation of protein kinase $\mathrm{C}(\mathrm{PKC})$, and more recently nicotinamide adenine dinucleotide phosphate (NADPH) oxidases, also referred to as NADPH oxidase (NOX), have been demonstrated to cause significant disruption to the regulatory processes that control homeostasis and stimulate several detrimental cellular signaling events, as illustrated in Figure 2 (29, 50, 84, 92, 129). Accumulating evidence has demonstrated the overproduction of reactive oxygen species (ROS) as the common denominator linking the altered metabolic pathways in the kidneys with disrupted renal hemodynamics known to be associated with DN. These pathways ultimately lead to inflammation, fibrosis, and endothelial dysfunction, as illustrated in Figure 2 $(30,92,129,201)$. Renal oxidative stress is often a consequence of upregulation of pro-oxidant enzyme-induced ROS production and concomitant depletion of antioxidants. Among the many enzymatic systems implicated in ROS generation in the kidney, the NOXs appear to be the most important contributors $(129,201)$. Excessive ROS production triggers renal fibrosis and inflammation and causes significant tissue damage by promoting lipid peroxidation, DNA damage, and protein modification, as well as mitochondrial dysfunction (197), as illustrated in Figure 2.

\section{ROS-Mediated Renal Inflammation in DKD}

Under physiological conditions, ROS plays an important role in cell signaling implicated in proliferation, differentiation, apoptosis, and immune defense in various cell lineages, including renal cells (197). However, under pathological situations, including in diabetes, the overpro- duction of ROS in the kidney is implicated in renal inflammation, affecting renal structure and function and subsequently leading to ESRD. Hyperglycemia-induced ROS production stimulates the recruitment of numerous inflammatory cells and production of inflammatory cytokines, growth factors, and transcription factors implicated in the pathological processes of DN (Fig. 2). Excessive infiltration of macrophages and $\mathrm{T}$ cells plays a pivotal role in initiating renal damage in $\mathrm{DN}(46,47)$. Activity and recruitment of these immune cells are often regulated by monocyte chemotactic protein-1 (MCP-1) (174). MCP-1 is predominantly expressed in renal monocytes, endothelial cells, and mesangial cells and is highly regulated by tumor necrosis factor-alpha (TNF- $\alpha$ ) and interleukin (IL)-1 (174, 191). In addition, MCP-1 was found to be upregulated in the glomerulus (124) and tubulointerstitium (273) in experimental models of type 1 diabetes. Increased oxidative stress has been demonstrated to significantly induce macrophage recruitment and MCP-1 levels (273). Moreover, urinary excretion of MCP-1 and MCP-1 levels in renal biopsies were significantly elevated in diabetic patients compared with healthy control individuals (250). Of importance, a direct correlation exists between MCP-1 excretion and the level of albuminuria (261). Additionally, the levels of IL-6 and TNF- $\alpha$ were found to be positively correlated with the progression of renal disease. IL-6 plays a key role in promoting mesangial cell proliferation, ECM expansion, and increasing endothelial cell permeability $(186,205)$, while TNF- $\alpha$ has been shown to exert a positive feedback loop on ROS production $(149,275)$. Furthermore, numerous studies have implicated nuclear factor-kappa $\mathrm{B}(\mathrm{NF}-\kappa \mathrm{B})$ as the main transcription factor in the initiation of inflammatory responses in the diabetes milieu (182). NF- $\kappa \mathrm{B}$ expression is increased in the kidneys in diabetic experimental models and activates mesangial cells to cause renal injury (106, 168). Key downstream effects of $\mathrm{NF}-\kappa \mathrm{B}$ include stimulation of adhesion molecules and expression of proinflammatory genes, including $M C P-1, T N F-\alpha$, and $I L-6$ (168, 186, 261, $275)$, which are all implicated in the development of DN.

\section{ROS-Mediated Renal Fibrosis in DKD}

Renal fibrosis is an integral pathological process in chronic kidney disease, including DKD. Chronic exposure of hyperglycemia drives the formation and accumulation of ECM proteins (collagen I, IV, and fibronectin) and contributes to the pathology and dysfunction of the kidney (42) (Fig. 2). Increased ROS production, along with the activation of profibrotic growth factors such as transforming growth factor-beta (TGF- $\beta$ ) and connective tissue growth factor (CTGF), leads to the recruitment of ECM-producing cells, which drives the progression of renal fibrosis and sclerosis (16). Enhanced production of vasoactive agents, such as angiotensin II (AngII), endothelin, and urotensin, has been shown to increase expression of TGF- $\beta$ in cultured renal cells and experimental animal models of DN (233, 272, 293). Furthermore, TGF- $\beta$ upregulates plasminogen activator inhibitor-1, which decreases ECM degradation (15) and CTGF, an important downstream prosclerotic cytokine of TGF- $\beta$ (218). In vitro studies have demonstrated that CTGF mediates TGF- $\beta$ induced elevation in the levels of fibronectin and collagen IV in renal cells (267). Although the kidney consists of at least 20 


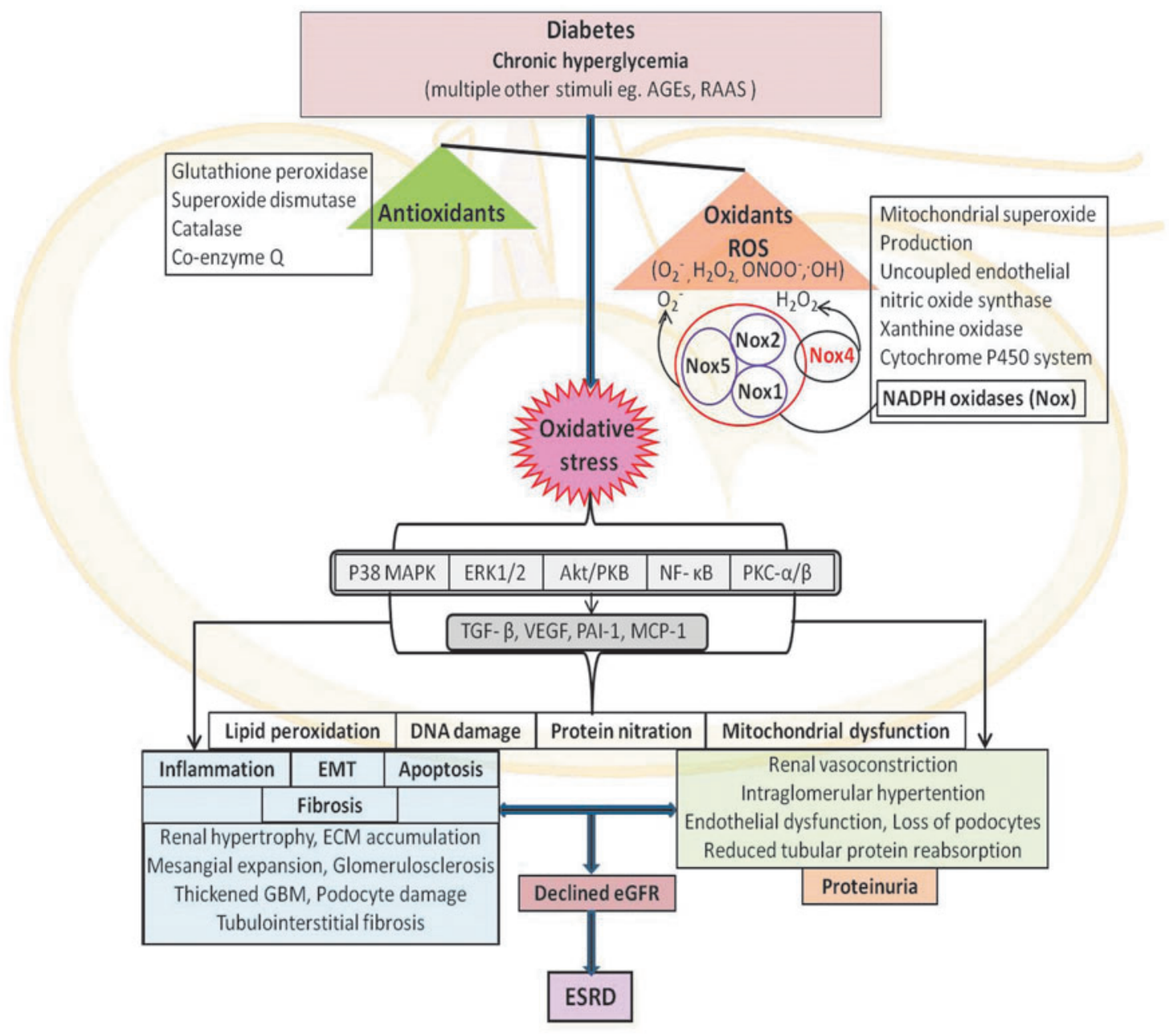

FIG. 2. Overview of mediators involved in the pathogenesis of DKD. AGEs, advanced glycation end products; Akt/ PKB, serine-threonine kinase; ECM, extracellular matrix; eGFR, estimated glomerular filtration rate; EMT, epithelialmesenchymal transition; ERK1/2, extracellular signal-related kinases 1 and 2; ESRD, end-stage renal disease; GBM, glomerular basement membrane; MCP-1, monocyte chemotactic protein-1; NF- $\kappa \mathrm{B}$, nuclear factor-kappa B; p38 MAPK, p38 mitogen-activated protein kinase; PAI-1, plasminogen activator inhibitor-1; PKB, protein kinase B; PKC- $\alpha$, protein kinase C- $\alpha$; PKC- $\beta$, protein kinase C- $\beta$; RAAS, renin-angiotensin-aldosterone system; ROS, reactive oxygen species; TGF$\beta$, transforming growth factor-beta; VEGF, vascular endothelial growth factor. To see this illustration in color, the reader is referred to the web version of this article at www.liebertpub.com/ars

cell types, fibroblasts are increasingly recognized as the prominent matrix-producing cells leading to ECM accumulation $(16,240)$. Several in vitro studies have emphasized the importance of fibroblast activation, but it should be kept in mind that no single type of cell in isolation is capable of initiating and sustaining the full scale of renal fibrosis. Renal fibrogenesis clearly necessitates the participation and interaction of many types of resident kidney cells, as well as infiltrating cells. The underlying cellular events leading to fibrogenesis are complex, which involves the activation of mesangial cells (55), dedifferentiation of epithelial and endothelial cells (16), and infiltration of bone marrow-derived fibrocytes $(27,260)$. ROS play a critical role in profibrotic pathways, including stimulation of many growth factors and cytokines such as TGF- $\beta 1$, CTGF, platelet-derived growth factor, and vascular endothelial growth factor (VEGF). Increased expression of these profibrotic factors in association with ROS results in an excessive buildup of ECM, which further exacerbates kidney injury (44).

\section{Physiological Oxidants and Antioxidants}

In the biological system, molecular oxygen undergoes a series of reductive biosynthetic steps forming several reactive oxygen intermediates commonly known as ROS, which are oxygen-derived, unstable, highly reactive, energized small molecules. ROS are either free radical molecules, including superoxide $\left(\mathrm{O}_{2}{ }^{\bullet-}\right)$, hydroxyl $\left({ }^{\bullet} \mathrm{OH}\right)$, peroxyl $\left(\mathrm{ROO}^{\bullet}\right)$, and alkoxyl $\left(\mathrm{RO}^{\bullet}\right)$, or nonradicals such as hypochlorous acid $(\mathrm{HOCl})$, ozone $\left(\mathrm{O}_{3}\right)$, singlet oxygen $\left({ }^{1} \mathrm{O} 2\right)$, and hydrogen peroxide $\left(\mathrm{H}_{2} \mathrm{O}_{2}\right)$. These nonradical ROS are oxidizing agents that are easily converted into free radicals (Fig. 3). Under physiological conditions, both endogenous and exogenous antioxidants interact with these oxidants to counteract the oxidative damage to cells (82). The antioxidant defense mechanisms include superoxide dismutase (SOD): manganese SOD and copper/zinc SOD; glutathione system: glutathione peroxidase and glutathione reductase; catalase; and coenzyme Q (Fig. 2). Antioxidant enzymes mainly convert 


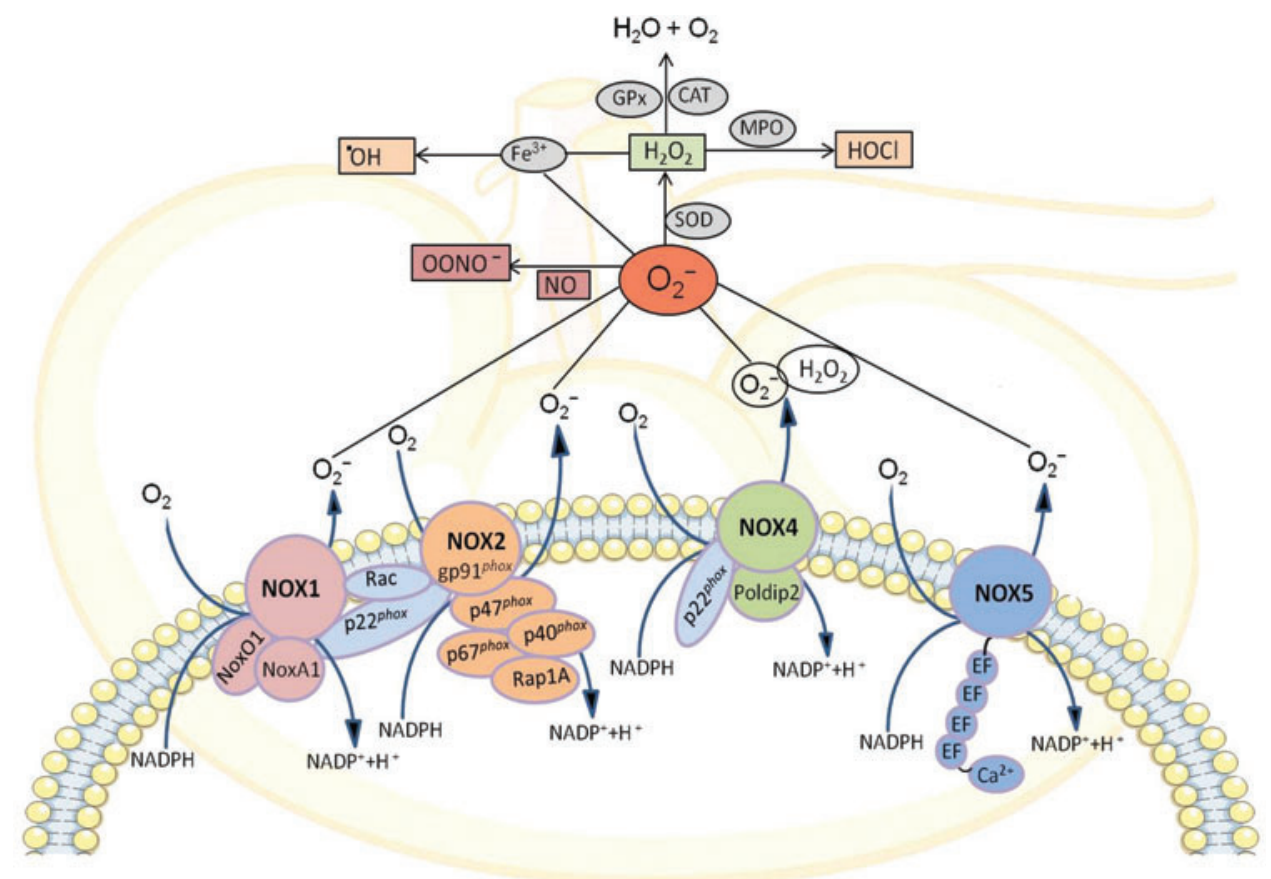

FIG. 3. Classical components of NOX catalytic subunits, NOX1, NOX2 $\left(\right.$ gp $91^{\text {phox }}$ ), NOX4, and NOX5, and their regulatory subunits $\left(\mathrm{p}^{4} 7^{\mathrm{phox}}, \mathrm{p67}^{\mathrm{phox}}, \mathrm{p} 40^{\mathrm{phlox}}\right.$, NoxO1, NoxA1, Rac1/2, and Rap 1A) along with sources of ROS generated endogenously by renal cells and key metabolic pathways for these NOX family enzymes. CAT, catalase; Gpx, glutathione peroxidase; $\mathrm{H}_{2} \mathrm{O}_{2}$, hydrogen peroxide; $\mathrm{HOCl}$, hypochlorous acid; MPO, myeloperoxidase; NADPH, nicotinamide adenine

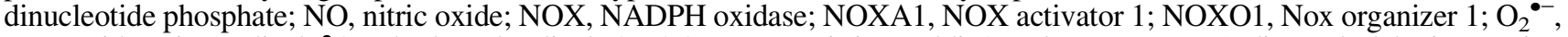
superoxide anion radical; ${ }^{\bullet} \mathrm{OH}$, hydroxyl radical; $\mathrm{ONOO}^{-}$, peroxynitrite; Poldip2, polymerase (DNA-directed) delta interacting protein 2; Rac, Ras-related C3 botulinum toxin substrate; SOD, superoxide dismutase. To see this illustration in color, the reader is referred to the web version of this article at www.liebertpub.com/ars

ROS into nonreactive oxygen molecules, ultimately forming water. The entire antioxidant redox system mainly utilizes NADPH as a chemical reductant, which is mostly produced by glucose-6-phosphate dehydrogenase (61). During the process of sequential generation of ROS, superoxide is the primary reactive oxygen intermediate, which is rapidly converted to $\mathrm{H}_{2} \mathrm{O}_{2}$ by spontaneous dismutation as well as by SOD-catalyzed dismutation. The intermediate $\mathrm{H}_{2} \mathrm{O}_{2}$ is then transformed to water either by catalase or by glutathione peroxidase, which utilizes reduced glutathione produced by glutathione reductase. On the other hand, myeloperoxidase converts $\mathrm{H}_{2} \mathrm{O}_{2}$ to the very toxic hypochlorous acid and hydroxyl radical is formed when superoxide and $\mathrm{H}_{2} \mathrm{O}_{2}$ interact with iron by Fenton reaction $(142,253)$. In addition, superoxide reacts with the nitrogen-containing oxidant, nitric oxide (NO), to form highly reactive nitrogen species, peroxynitrite $\left(\mathrm{OONO}^{-}\right)$, which reduces NO bioavailability causing NO toxicity to the cells (79) (Fig. 3).

\section{Sources of ROS in the Kidney}

Multiple intracellular mechanisms are involved in ROS production in the kidney, including xanthine oxidase, cytochrome P450 systems, uncoupled NO synthase (NOS), mitochondrial respiratory chain, and NOXs $(92,152)$ (Fig. 3). Under physiological conditions, xanthine oxidase produces an undetectable amount of ROS in the kidney via the purine metabolism pathway. Xanthine oxidase-derived ROS is found to be associated with endothelial dysfunction in patients with coronary disease and contractile dysfunction in heart failure (228). However, its contribution to DKD remains poorly understood. On the other hand, the cytochrome P450 system has an indirect role in ROS production in kidney. A study by Eid et al. demonstrated that cytochrome P450, particularly CYP4A, produces ROS via activation of NOX, causing renal cell injury and death in diabetic mice (74). Uncoupled NOS contributes to ROS generation, which leads to low levels of endothelial NO bioavailability, resulting in vascular endothelial dysfunction in DKD $(105,227)$. The most important source of these ROS in the kidney remains controversial. In the context of DKD, it has been suggested that mitochondrial generation of superoxide and NOXderived ROS play a significant role in the kidney $(84,96,128$, 156). NOXs are particularly important as they have been identified to produce ROS not as a by-product, but as their sole biological function (18). In this section of review, we will discuss the involvement of ROS in the pathogenesis of DKD mainly derived from NOX and mitochondrial dysfunction.

\section{NADPH Oxidases}

Over the past several years, significant progress has been made to better understand the role of NOXs in renal ROS biology and the contribution of individual NOX isoforms in the pathogenesis of DKD. Under physiological conditions, most NOXs have very low or no constitutive activity, but their 
expression at the transcription or translational level may be increased, or the enzyme could be activated in disease states such as hypertension and diabetes. In these situations, the increased $\mathrm{NOX}$-generated $\mathrm{O}_{2}^{-}$surpasses the handling capacity of the endogenous antioxidant system, thus leading to increased oxidative stress and ultimately tissue injury. In the second half of 20th century, it was demonstrated that NOX-derived superoxide is responsible for the oxidative burst in the phagocytes $(11,221)$. Later in 1986, gp91phox, commonly known as NOX2, was cloned as the first catalytic subunit of phagocyte NOXs $(222,249)$. After the identification of NOX2, several ROS-producing enzymes have been identified in the nonphagocytic cells, which differ at the molecular level, but share similar structural homology with phagocyte NOX, NOX2. These enzymes together are now considered as members of the NOX family. To date, seven known isoforms of NOXs - NOX2 (prototype NOX, formerly termed gp91phox), NOX1, NOX3, NOX4 (formerly termed Renox), NOX5, and dual oxidases (DUOX1 and DUOX2) - have been identified in various tissues. These NOX enzymes share common, conserved structural properties, which include the NADPH binding site at the very C-terminus, the flavin adenine dinucleotide (FAD) binding region in proximity of the C-terminal transmembrane domain, six conserved transmembrane domains, and four conserved hemebinding histidines (18). All NOX isoforms are transmembrane proteins that transfer electrons across the biological membrane from NADPH to reduce molecular oxygen to superoxide $\left(\mathrm{O}_{2}{ }^{-}\right)$ (10), as illustrated in Figure 3.

$$
\mathrm{NADPH}+2 \mathrm{O}_{2} \stackrel{\mathrm{NOX}}{\longrightarrow} \mathrm{NADP}^{+}+\mathrm{H}^{+}+2 \mathrm{O}_{2}^{-}
$$

\section{NOX Catalytic Isoforms and Regulatory Subunits}

An assembly of individual catalytic isoforms of NOX and their respective regulatory subunits is required for the activation and thereby generation of superoxide in the tissue. The classic prototype NOX (NOX2) was first characterized in phagocytes and is a multicomponent enzyme consisting of the highly glycosylated membrane-bound catalytic subunits, gp91 ${ }^{\text {phox }}$ and $\mathrm{p} 22^{\text {phox }}$, which associate with regulatory cytosolic subunits, p4 $7^{\text {phox }}, \mathrm{p} 67^{\text {phox }}, \mathrm{p} 40^{\text {phox }}$, Rac GTPase, and Rap 1A, during the process of enzyme activation (Fig. 3) (23, 242). Following stimulation, the cytosolic subunits translocate to the membrane, where they interact with the flavocytochrome to form the activated oxidase, leading to transfer of electrons from NADPH to molecular oxygen, thereby generating large amounts of extracellular superoxide (242) that plays a pivotal role in host defense against microbial infections (2). Two Nox2 splice variants, named Nox $2 \mathrm{~S}$ and Nox $2 \beta$, have been identified with Nox $2 \beta$ being suggested to have a functional role in the regulation of NOX activity in macrophages (109). Other NOX isoforms variably require the binding of distinct regulatory subunits for their activity. For instance, NOX1 binds to $\mathrm{p} 22^{\text {phox }}$, Rac1, and to homologs of $\mathrm{p} 47^{\text {phox }}$ and $\mathrm{p} 67^{\text {phox }}$ called NOX organizer 1 (NOXO1) and NOX activator 1 (NOXA1). NOX1 shares $60 \%$ homology with NOX2 and was identified as the first homolog of NOX2 $(13,241)$. Two Nox1 splice variants, Nox1-L and Nox1-S, have been identified and are considered to be functionally distinct (108). NOX3 was first identified by Kikuchi et al. in 2000 and shares 56\% homology with NOX2 (136). NOX3 can function as a heterodimer with $\mathrm{p} 22^{\text {phox }}$, but its activity is enhanced by interaction with $\mathrm{p} 47^{\mathrm{phox}}$ and $\mathrm{p} 67^{\mathrm{phox}}$, although it does not seem to require Rac GTPase (2). NOX4 was identified by Geiszt et al. in 2000 and initially characterized as a renal gp91 ${ }^{\text {phox }}$ homolog (91). However, it was found that NOX4 is relatively distinct in structure from other NOX homologs. NOX4 shares only 39\% homology with NOX2 and $35 \%$ homology with NOX1 (91). The activation of NOX4 also requires interaction with $\mathrm{p} 22^{\text {phox }}$, but differs from the other NOX isoforms, in that it does not require any other cytosolic regulatory subunit for ROS production. In addition, the interaction of NOX4 with Rac GTPase remains unclear (99). NOX4 appears to be constitutionally active, with regulation thought to occur mainly at the transcriptional level (167). Furthermore, interaction of NOX4/p22phox with Poldip2, a polymerase (DNA-directed) delta-interacting protein 2 , has also been identified as a positive regulator in vascular smooth muscle cells (163). Interestingly, recent reports suggest that NOX4 may have a propensity for predominant $\mathrm{H}_{2} \mathrm{O}_{2}$ rather than $\mathrm{O}_{2}{ }^{\bullet-}$ production, in marked contrast to NOX2 (64, 167). The biochemistry behind this is controversial and one hypothesis is that the superoxide produced by NOX4 is rapidly dismutated to $\mathrm{H}_{2} \mathrm{O}_{2}$, which makes it practically undetectable from superoxide released from NOX4 $(16,153)$. In addition, NOX4, unlike the other NOX isoforms, has an extended E-loop whose alteration can switch it from an $\mathrm{H}_{2} \mathrm{O}_{2}$ generating system into an $\mathrm{O}_{2}{ }^{-}$-generating system. Depending on the cellular context, minor structural changes in the E-loop may influence the mechanism of ROS production by these NOX enzymes (247). In human lung tissue, four Nox 4 splice variants, Nox4B, Nox4C, Nox4D, and Nox4E, have been identified, but it remains unclear which of these splice variants is the most important in the kidney (100). NOX5 is the most recently identified member of the NOX family and is structurally distinct. In humans, the Nox5 gene is found on chromosome 15, and five known splice variants of Nox $5-\alpha$, $-\beta,-\delta,-\gamma$, and a truncated variant (Nox5-S) (88) have been described, with the Nox $5-\alpha$ and $-\beta$ splice variants producing functional ROS-generating proteins (19). Despite sharing significant homology to NOX1 and NOX2, NOX5 possesses an amino-terminal calmodulin-like domain with 4 binding sites for $\mathrm{Ca}^{2+}$ and does not require other subunits for its activation. The increase in intracellular calcium and the consequent binding of $\mathrm{Ca}^{2+}$ to NOX5 causes an increase in superoxide generation (180). On the other hand, the dual oxidases, DUOX1 and DUOX2, were first identified in the thyroid gland in 1999 and 2000, respectively, by Dupuy et al. (71) and by De Deken et al. (58). These enzymes share 50\% homology with NOX2 and have a similar membrane domain to that of NOX14, an EF-hand region such as NOX5, and a seventh transmembrane domain at the N-terminus (49). In addition, two maturation factors, DUOXA1 and DUOXA2, have been identified in 2006 by Grasberger et al. (102). Unlike, other NOX isoforms, interaction of DUOX proteins with $\mathrm{p} 22$ phox is unclear and these enzymes can be activated through $\mathrm{Ca}^{2+}$ without requiring any cytosolic regulators $(57,262)$.

\section{Localization and Expression of NOX Isoforms in the Kidney}

The NOXs are expressed in many tissues and mediate diverse biological functions, including regulating intracellular 
signaling. Initially, NOX1 was thought to be found in colon epithelium and to play a role in host defense and cell growth. However, recent studies demonstrate expression of NOX1 in variety of other cell types, including vascular smooth muscle cells, endothelial cells, uterus and placenta, and kidney (18, 124). NOX2 is the catalytic subunit of the respiratory burst oxidase in phagocytes and plays a role in innate immunity, but it is also expressed in nonphagocytic cells such as vascular, cardiac, renal, and neural cells (242); NOX3 is found in fetal tissue and the adult inner ear and is involved in vestibular function $(12,43)$. Current evidence indicates that NOX3 has a developmental role in otolith biosynthesis. Its absence causes a failure in this process, leading (in the adult animal) to vestibular dysfunction. Thus, the linkage between NOX3 and vestibular function is quite an indirect one (199). NOX4 was originally termed Renox (renal oxidase) because of its abundance in the kidney and thought to be specific to the kidney, but recently it has been also found in nonrenal cells, including osteoclasts, neurons, fibroblasts, vascular smooth muscle cells, cardiomyocytes, and endothelial cells (48, 63, $258,269,277)$. The subcellular localization of NOX4 remains controversial; this is partly because of the unavailability of reliable anti-NOX4 antibodies. Nevertheless, NOX4 has been shown to be associated with intracellular membranes of compartments or cell organelles such as focal adhesions, endoplasmic reticulum, plasma membrane, mitochondria, and nucleus $(3,18,22,113,153,167,206)$. The human NOX isoform, NOX5, is a $\mathrm{Ca}^{2+}$-dependent homolog found in testis and lymphoid tissue, as well as in vascular and renal cells (14). While most NOX enzymes are present in rodents and humans, the mouse and rat genomes do not contain the Nox5 gene (14). Among these isoforms, the expression of NOX1, NOX2, NOX4, and NOX 5 is identified in the target organs of diabetic complications, including blood vessels, retina, kidney, and peripheral nerve (18). Currently, there is no evidence of involvement of NOX3, DUOX1, and DUOX2 in diabetes and its complications. Although there has been enormous progress in the biochemical, chemical, and structural characterization of NOX isoforms, the regulation and function of each NOX remain unclear, but it is evident that NOX enzymes are critical for normal biological responses and that they contribute to end-organ injury in diabetes, cardiovascular and renal disease, hypertension, and atherosclerosis. Moreover, the relative importance of NOX1, NOX2, NOX4, and NOX5 isoforms in DN remains unclear. Experimental evidence shows that within the kidney, NOX1, NOX2, NOX4, and NOX5 isoforms are expressed in glomerular cells, including mesangial cells, vascular smooth muscle cells, endothelial cells, podocytes, tubular epithelial cells (proximal and distal tubular cells), and interstitial fibroblasts $(92,95)$. Localization and expression of NOX catalytic isoforms and its regulatory subunits in the renal tissues and cells are summarized in Table 1.

\section{NOX-Derived ROS in DKD}

At basal levels, ROS may function as second messengers to influence redox-sensitive signal transduction pathways (237). However, in pathological conditions, including DKD, NOX-dependent overproduction of ROS leads to an imbalance of redox homeostasis in the kidney. Chronic hyperglycemia along with various diabetes-associated stimuli, including AGEs, AngII, and TGF- $\beta$, participates in increasing expression and the activity of various NOX isoforms, including NOX1, NOX2, NOX4, and NOX5, and thereby generating unwanted amounts of ROS, causing oxidative damage to the renal tissues $(18,21,22,74,92,96,114,124$, 251, 252, 269). Thus, NOX isoforms may represent new therapeutic targets for renoprotection in DKD. In this section of the review, we will discuss the experimental evidences supporting the involvement and contribution of specific NOX isoform-derived ROS implicated in glomerular injury and tubulointerstitial fibrosis, both important features of DKD (Figs. 4-6).

\section{NOX-Mediated Glomerular Injury in DKD}

All NOX isoforms have been found to be upregulated in glomerular cells (mesangial cells, endothelial cells, and podocytes) in response to high glucose in vitro as well as in experimental models of diabetes $(1,18,21,22,74,96,97,99$, 114, 124, 164, 251, 252, 269, 294). Indeed, ROS (superoxide and $\mathrm{H}_{2} \mathrm{O}_{2}$ ) have been recognized to be important mediators of early mesangial cell hypertrophy, mesangial expansion, accumulation of ECM proteins, glomerulosclerosis, endothelial

Table 1. Localization of NOX Isoforms and Regulatory Subunits in the Kidney

\begin{tabular}{|c|c|c|c|c|c|c|c|c|}
\hline \multirow[b]{2}{*}{ Renal compartments } & \multicolumn{4}{|c|}{ Nox isoforms } & \multicolumn{3}{|c|}{ Nox regulatory subunits } & \multirow[b]{2}{*}{ References } \\
\hline & Noxl & Nox 2 & Nox4 & Nox5 & $p 22^{\text {phox }}$ & $p 47^{\text {phox }}$ & p67 $7^{\text {phox }}$ & \\
\hline Cortex & + & + & + & + & + & + & + & $96,124,177$ \\
\hline Glomerulus & + & + & + & + & + & + & + & 124,140 \\
\hline Vascular smooth muscle cell & + & & + & + & & & & 202,269 \\
\hline Mesangial cell & + & + & + & + & + & + & + & $80,90,128,213$ \\
\hline Endothelial cell & + & & + & + & & & & 180,202 \\
\hline Podocyte & + & + & + & + & + & + & & $104,114,124,245$ \\
\hline Distal tubule & & + & & & + & + & + & $7,36,80,236$ \\
\hline Proximal tubule & + & + & + & + & & & & $80,91,114,187,229,236,284$ \\
\hline TAL & + & + & + & & + & + & & $115,160,170$ \\
\hline CCD & & & + & & + & + & + & $36,81,192,243$ \\
\hline MCD & & & & & + & + & + & 36 \\
\hline Macula densa & & + & + & & + & + & + & $36,286-288$ \\
\hline
\end{tabular}

CCD, cortical collecting duct; MCD, medullary collecting duct; TAL, thick ascending limb of the loop of Henle. 


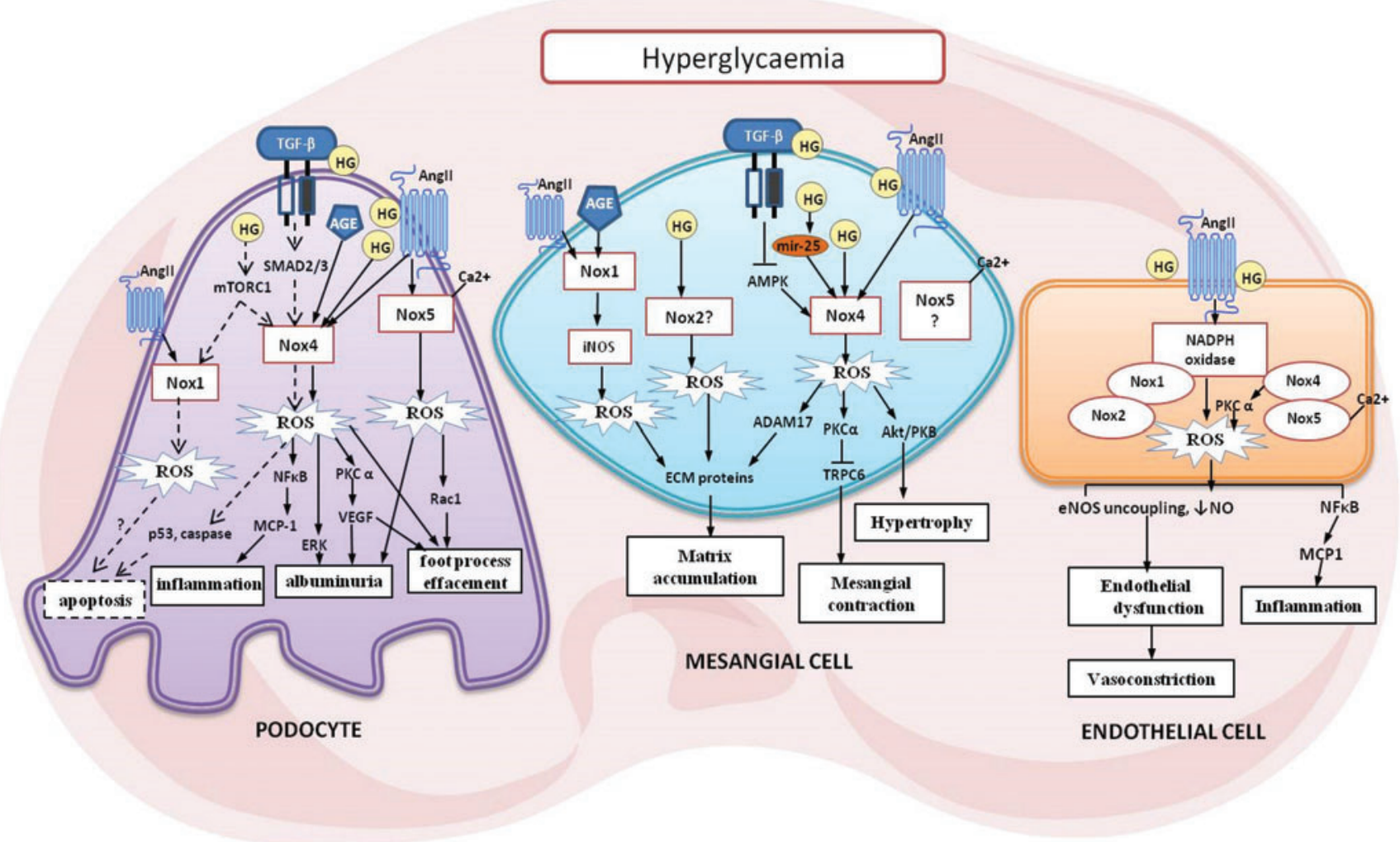

FIG. 4. Key mediators of glomerular cell injury in diabetes. The three key renal cell types that make up the glomeruli include the podocytes, mesangial cells, and endothelial cells. As shown, several possible mechanisms can lead to pathological changes implicated in DKD. ROS generation by NOX initiates and mediates the signaling cascades leading to cellular injury. See text for detail. ADAM17, ADAM metallopeptidase domain 17; AMPK, 5' AMP-activated protein kinase; AngII, angiotensin II; eNOS, endothelial nitric oxide synthase; HG, high glucose; mTORC1, mammalian target of rapamycin complex 1; TRPC6, transient receptor potential cation channel, subfamily $\mathrm{C}$, member 6. To see this illustration in color, the reader is referred to the web version of this article at www .liebertpub.com/ars

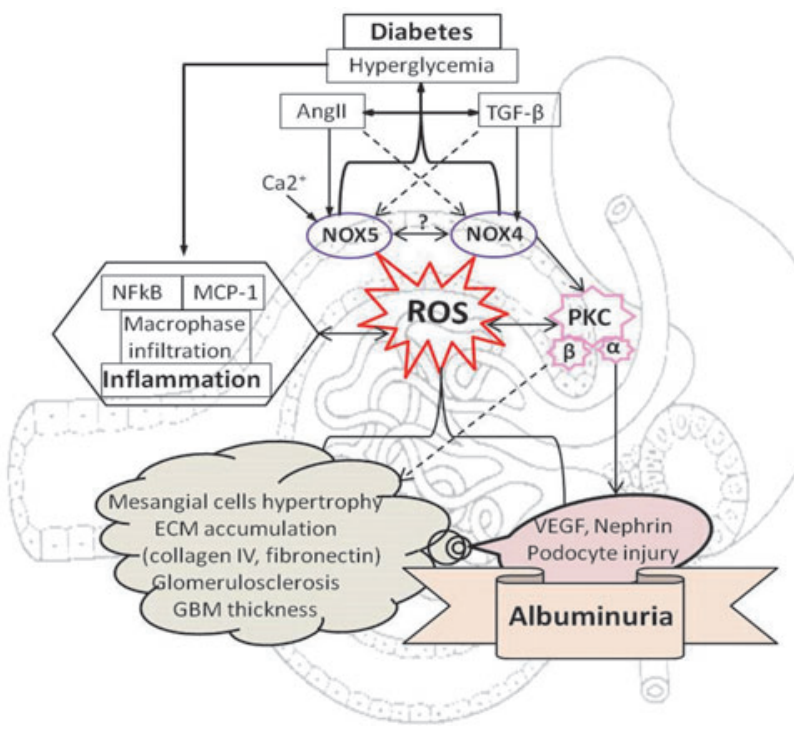

FIG. 5. NOX4 and NOX5-mediated glomerular injury and albuminuria in diabetes. To see this illustration in color, the reader is referred to the web version of this article at www.liebertpub.com/ars dysfunction, podocyte apoptosis, and subsequent development of albuminuria, as well as disruption of glomerular hemodynamics in $\operatorname{DKD}(1,18,21,22,74,96,97,99,114$, 124, 164, 239, 251, 252, 269, 294) (Fig. 4). Among NOX isoforms, NOX4 and more recently also NOX5-derived ROS have been suggested to mediate glomerular injury and podocytopathy, leading to albuminuria, which is considered a key feature of DKD $(21,22,96,97,99,114,124,251)$ (Fig. 5).

\section{NOX-Mediated Mesangial Hypertrophy, ECM Accumulation, and Glomerulosclerosis}

\section{NOX4}

NOX4 is the most extensively studied isoform of NOX in the context of DKD and this is mainly because NOX4 is highly expressed in the kidney and is upregulated in diabetes. The contribution of NOX4-derived ROS in DKD perpetuating glomerular hypertrophy and mesangial expansion is supported by numerous experimental studies $(95,124,164)$. Enhanced ROS level in response to high glucose was found to be associated with increased expression of Nox4 in the mesangial cells $(22,75,203,231)$. NOX4-derived ROS drives uncoupling of endothelial NOS (eNOS), and a decrease in NO bioavailability (eNOS dysfunction) in diabetes can 


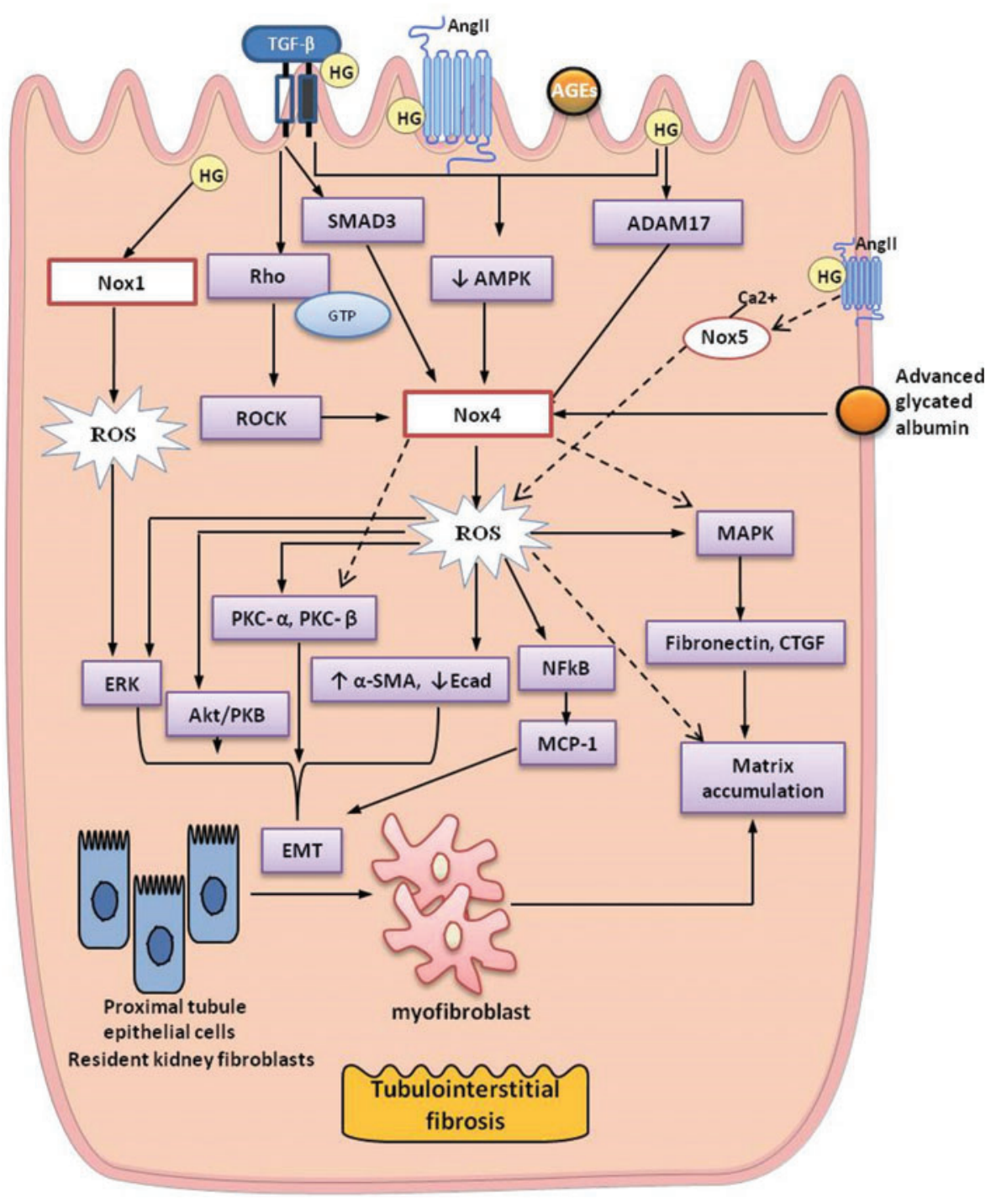

FIG. 6. Key mediators of tubulointerstitial fibrosis in diabetes. $\alpha$ SMA, alpha-smooth muscle actin; Ecad, epithelial cadherin; ROCK, Rho-associated protein kinase; SMAD 3, SMAD family member 3. To see this illustration in color, the reader is referred to the web version of this article at www.liebertpub .com/ars initiate fibrotic injury to mesangial cells, suggesting that NOX4 functions upstream of eNOS (75). In addition, blockade of NOX4-dependent eNOS dysfunction by the antioxidant sestrin 2-dependent AMP-activated protein kinase showed an antifibrotic effect in mesangial cells exposed to high glucose (75). Another study has shown that high-glucose-induced ROS production by NOX4 in mesangial cells is mediated by thioredoxin-interacting protein (TxNIP) (231).

With regard to the in vivo studies, it is postulated that during the early stages of diabetes, increased expression of Nox 4 and the subsequent ROS production in glomeruli of streptozotocin (STZ)-induced diabetic rats mediate oxidative damage to the glomeruli, leading to glomerular hypertrophy and increased fibronectin expression (96). In addition, blocking of ROS production in the renal cortex by treating with antisense oligonucleotides to Nox4 was reported to reduce fibronectin expression and ECM accumulation associated with reduced renal hypertrophy in diabetic rats (96). This finding was supported by another study from the same group in establishing a link between NOX4 and ECM production and has identified that the matrix metalloproteinase ADAM17 can modulate Nox4 expression in the kidney (85). Indeed, we have recently shown that global genetic deletion of Nox4 significantly attenuated the diabetes-induced increased mesangial expansion, glomerulosclerosis, and accumulation of ECM proteins (collagen IV and fibronectin) via a reduction in ROS production in a mouse model of type 1 diabetes $(124,251)$. In addition, deletion of Nox4 in diabetic mice was also associated with reduction in glomerular macrophage infiltration and downregulation of $M C P-1$ and $N F$ $\kappa B$, important mediators of inflammation in diabetes (124). Furthermore, of clinical relevance, the administration of a novel NOX1/4 inhibitor, GKT137831 (www.genkyotex.com), in diabetic mice provided similar degree of renoprotection compared with the findings observed in Nox4 knockout (KO) mice (124). This renoprotective effect of GKT137831 was further demonstrated by Gorin et al. in an OVE26 mouse model of type $1 \mathrm{DN}$ (97). In addition, recently, we have shown that podocytespecific Nox4 deletion provided protection against glomerular injury by attenuating various glomerular ultrastructural changes, including glomerulosclerosis, mesangial expansion, and accumulation of ECM proteins, as well as reduction in GBM thickness in diabetic mice (125). This study supports the hypothesis that there is a potential cross-talk between podocytes and other glomerular cells, which are involved in the process of 
glomerulosclerosis. NOX4 was also found to play a role in cardiac fibrosis and hypertrophy via activation of Akt $/ \mathrm{mTOR}$ and NF- $\kappa$ B signaling pathways (289).

Involvement of AngII or TGF- $\beta$ alone or in association with high glucose in the regulation of NOX4-derived ROS-induced signaling in renal cells, including mesangial cells, has also been reported by several studies $(74,117,124,166)$. Indeed, recently, TGF- $\beta$ was found to induce both the activity of NOX and expression of Nox 2 and Nox 4 , indicating that this growth factor induces production of ROS in kidney myofibroblasts (24). In addition, silencing of Nox4 markedly inhibited TGF$\beta$-induced stimulation of NOX activity, and inhibition of transforming growth factor receptor 1 (TGF- $\beta$ R 1 ) blocked Smad3 phosphorylation, reduced TGF- $\beta$-enhanced NOX activity, and decreased expression of Nox4 (24). It is postulated that inactivation of $5^{\prime}$ AMP-activated protein kinase (AMPK) is implicated in driving the effect of TGF- $\beta / \mathrm{NOX} 4$ signaling on ECM accumulation (203). AMPK is a stress-induced protein critical in suppression of ROS and thus protects against oxidative stress in diabetes (33).

Renal tissue AngII activates NOX in mesangial cells and angiotensin-converting enzyme (ACE) inhibitors were shown to reduce renal and urine ROS production in STZinduced diabetic rats (196). Another study has found a link between NOX4-derived ROS and AngII-mediated activation of Akt/protein kinase B (PKB) in mesangial cells (99). Recently, NOX4 was identified as a mediator of peroxynitritedependent eNOS uncoupling in response to AngII, suggesting the involvement of AngII/Nox4 in mesangial cells and in eNOS dysfunction, thus imposing fibrotic injury to mesangial cells (154). Involvement of AngII-induced generation of ROS acts through Nox4 as upstream activators of extracellular signalrelated kinases 1 and 2 (ERK1/2), PDK-1, and Akt/PKB that lead to cell hypertrophy and increased fibronectin expression in the kidney $(16,21,95,96,99,154)$.

Furthermore, there is a link between NOX-derived ROS and certain PKC isoforms, including PKC- $\alpha$ and PKC- $\beta$, in the pathogenesis of $\operatorname{DKD}(93,251)$. Indeed, overactivation of PKC- $\beta$ was found to upregulate expression of TGF- $\beta$ and to increase ECM protein components in the glomeruli of diabetic rats via NOX4-dependent ROS formation (147). Recently, we have shown that NOX4-derived ROS can activate PKC- $\alpha$ within the kidney, thereby promoting glomerular injury in experimental diabetes $(125,251)$. Another study has also shown a link between NOX-derived ROS, PKC- $\alpha$, and advanced oxidation protein product (AOPP) in renal fibrosis. Exposure of AOPPs to mesangial cells resulted in increased expression of collagen IV, fibronectin, TGF- $\beta$, p47phox, p22phox, and Nox4, as well as increased activity of PKC- $\alpha$, suggesting involvement of the PKC/NOX-dependent pathway in glomerular injury (266). However, it is still a matter of debate if NOX4 is upstream or downstream of PKC- $\alpha$. Nevertheless, recently, we have shown that deficiency of Nox4 in podocytes was associated with a decrease in protein expression of PKC- $\alpha$ in diabetic mice with subsequent reduction in glomerular injury (125) (Figs. 4 and 5).

MicroRNAs are also important modulators of renal function and disease. Indeed, recent studies also show the association of NOX4 with expression of certain microRNAs, particularly microRNA-25 (mir-25) in diabetes-associated renal pathology (86). Downregulation of mir-25 in mesangial cells in response to high glucose or in the diabetic kidney was found to be associated with increased expression of Nox 4 and subsequent increase in ROS production in the kidney (86). In addition, microRNA-146a attenuated high-glucose/thrombininduced endothelial inflammation in human aortic endothelial cells by inhibiting Nox4 expression (264) (Fig. 4).

While the above evidence supports the fact that NOX4 plays a significant role in mediating glomerular injury in diabetes, its role remains to be more clearly defined. Babelova et al. (9) did not find an upregulation of Nox4 in the kidneys of C57/BL6 diabetic mice and Nox4 deficiency did not attenuate nephropathy. This may be due to the fact that C57/BL6 mice are relatively resistant to the development of the typical morphologic features of DN (28). Nevertheless, the majority of studies have indicated that contribution of NOX4 is critical in ROS-mediated renal glomerulopathy in diabetes.

\section{NOX5}

Few studies have investigated the involvement of NOX5derived ROS in development of glomerular injury in diabetes. This is partly because of the lack of the Nox 5 gene in mice or rats, making it difficult for experimental studies. However, recently, Holterman et al. (114) have shown increased glomerular injury in Nox5 transgenic mice with selective expression of Nox 5 in the podocytes in the presence of diabetes and hypertension. However, the translation relevance of such transgenic approaches remains to be fully defined.

\section{NOX2}

NOX2-derived superoxide production from macrophages as well as from resident renal cells may also contribute to renal injury. Indeed, we have previously shown increased macrophage infiltration and expression of MCP-1 and vascular cell adhesion protein-1 (VCAM-1) in kidneys of diabetic ApoE KO mice in association with increased nitrotyrosine expression, a marker of oxidative stress (238). The expression of Nox2 and enhanced membrane translocation of $\mathrm{p} 47^{\text {phox }}$ were reported in the kidneys of diabetic mice (7). Supporting this statement, studies by Shi et al. reportedly demonstrated that AOPPs promote inflammatory responses in the diabetic rat kidney through the upregulation of membrane expression of Nox 2 and $\mathrm{p} 47^{\text {phox }}(235)$. Moreover, a recent study has shown that deletion of Nox 2 did not attenuate glomerulosclerosis in diabetic mice (281). However, our group has recently reported that global deletion of Nox 2 in diabetic mice was associated with increased susceptibility to infections and $100 \%$ mortality at week 20 of diabetes (103) with animals surviving only when placed on prophylactic antibiotic treatment. Nevertheless, one cannot exclude a potential role for partial Nox 2 inhibition, but the lethality of severe Nox 2 deficiency in hyperglycemic states is likely to narrow the therapeutic window of such an approach.

\section{NOX1}

On the other hand, ROS derived from NOX1 has been implicated in the development of atherosclerosis $(103,234)$ and hypertension (171), but very little is known about the potential role of NOX1 in DKD. It was reported that AngII infusion promotes oxidative stress in the renal cortex of mice via increased mRNA expression of Noxl and $p 22^{\text {phox }}$ (35). A recent study has suggested that NOX1 plays a key role in the modulation of systemic and renal oxidative stress and redox-dependent signaling, but not in the elevation of blood 
pressure in a model of chronic AngII-dependent hypertension (279). In Dahl salt-sensitive hypertensive rats, which exhibit proteinuria and increased cortical collagen content, enhanced renal cortical expression of Nox 1 and $\mathrm{p} 22^{\text {phox }}$ in association with activation of the ERK1/2 pathway was demonstrated (189). In addition, NOX1 was suggested to play a role in the modulation of renal oxidative stress and redox-dependent signaling of c-Src, p38 mitogen-activated protein kinase (MAPK), c-Jun N-terminal kinase (JNK), and focal adhesion kinase (279). In addition, a study by Gao et al. showed that silencing of Nox 1 , but not Nox 2 or Nox4, suppressed the levels of superoxide and peroxynitrite, as well as reduced expression of TGF- $\beta$ and fibronectin in human mesangial cells (90). However, recently, we have shown that deletion of NOX1 in diabetic ApoE $\mathrm{KO}$ mice did not provide protection against glomerular injury (124). These authors reported that NOX1derived ROS-mediated fibrogenesis acts via activation of inducible NOS and the latter is involved in mediating AGE-driven ECM remodeling via peroxynitrite formation (39). Thus, the role of NOX1 warrants further elucidation.

Another important feature of DN is impaired contractility of mesangial cells in diabetes, thus altering normal glomerular hemodynamics and contributing to diabetic hyperfiltration. TRPC6 is a member of the TRPC family of $\mathrm{Ca}^{2+}$-permeable cation channels, which regulates $\mathrm{Ca}^{2+}$ signaling and participates in mesangial cell contractile function. In this study, Graham et al. found that NOX4-derived ROS in the hyperglycemic setting downregulates TRPC6 expression via activation of $\mathrm{PKC}-\alpha$, impairing the contractile function of mesangial cells and thus contributes to diabetic hyperfiltration (101). However, the role of TRPC6 in glomerular pathology was found to be cell specific. In particular, elevated TRPC6 channel activity mediated by increased ROS may account for podocyte apoptosis and diabetic glomerulosclerosis (161). With the knowledge that NOX5 is regulated by $\mathrm{Ca}^{2+}$ levels, the role of NOX5 in the contractile function of mesangial cells in diabetes warrants further investigation.

\section{NOX-Mediated Glomerular Endothelial Dysfunction}

Modification of glomerular capillaries and endothelial dysfunction are key contributors to epithelial cell injury in the progression of DKD. The hemodynamic alterations observed in early diabetes such as increased glomerular intercapillary pressure are partly attributed to endothelial dysfunction. With the glomerular endothelial cell strategic location at the interface between the blood compartment and the glomerular mesangium, it serves an important role in regulating glomerular microcirculation. In diabetic conditions, superoxide anions interact with NO, which is produced physiologically by constitutive sources such as the eNOS. This process leads to the formation of peroxynitrite $\left(\mathrm{ONOO}^{-}\right)$, which binds to tyrosine and other protein residues yielding cytotoxic compounds such as nitrotyrosine (198). While diabetes is associated with reduced NO bioavailability, it is observed that in early stages of DN, eNOS expression in the kidney is increased (60). There is paucity of information on the involvement of NOXs specifically in glomerular endothelial dysfunction. Gene expression of the catalytic subunits, Nox1, Nox2, Nox4, and Nox5, and regulatory subunits, p22phox, p67phox, and p47phox, has been demonstrated in cultured endothelial cells $(1,127,294)$.
Numerous studies have demonstrated that in the diabetic endothelium, eNOS represents the predominant source of superoxide, following activation of the Ang-II-dependent NOX pathway $(38,121,193)$. Indeed, a study by Jaimes et al. (120) found that exposure of human renal glomerular endothelial cells (HRGECs) to either AngII or high glucose resulted in increased expression of cyclooxygenase 2 (COX2) and uncoupled eNOS, and this effect was prevented by the use of an NOX nonspecific inhibitor, diphenylene iodonium (DPI). eNOS dysfunction in the kidney has been reported in experimental models of type 1 diabetes. Indeed, eNOS KO diabetic mice appeared to have increased albuminuria and mesangial matrix expansion, as well as advanced renal lesions such as arteriolar hyalinosis and Kimmelstiel-Wilson nodules (184). Recently, NOX4-derived ROS was identified as a critical mediator in eNOS uncoupling in mesangial cells (75). This is intriguing given the current findings that $\mathrm{NOX} 4$ generates predominantly $\mathrm{H}_{2} \mathrm{O}_{2}$ rather than superoxide. This property of NOX4 has important implications in NO signaling since $\mathrm{H}_{2} \mathrm{O}_{2}$, unlike superoxide, does not react with NO to form peroxynitrite and may even stimulate eNOS activity. However, one explanation is that even if NOX4 generates relatively less superoxide than $\mathrm{H}_{2} \mathrm{O}_{2}$, the release of superoxide is still capable of reacting with $\mathrm{NO}$ to form peroxynitrite, leading to endothelial dysfunction. One cannot exclude the fact that effects of peroxynitrite on individual cells could occur not only as a result of production by the cells themselves but also by adjacent cells of a different lineage. For example, the effect of peroxynitrite in endothelial cells could have occurred as a result of peroxynitrite generated by adjacent cells, including podocytes and mesangial cells. Another possible explanation is that mesangial cells express not only Nox4 but also Nox1, Nox2, and Nox5. $\mathrm{H}_{2} \mathrm{O}_{2}$ may stimulate Nox1 or Nox 2 or Nox 5 , which predominantly produces superoxide, thus ultimately causing endothelial dysfunction. Indeed, El Jamali et al. demonstrated a regulation of Nox 2 and Nox 5 by $\mathrm{H}_{2} \mathrm{O}_{2}$ through a $\mathrm{Ca}(2+) / \mathrm{c}-\mathrm{Abl}$ signaling pathway $(77,78)$.

Endothelial cells have also been shown to participate in glomerular inflammation. Glomerular endothelial cells in response to AngII was found to be associated with increase in ROS production and p47phox protein levels, as well as inflammatory parameters such as NF- $\kappa$ B and MCP-1 (201a). The link between inflammation and a specific NOX isoform, Nox4, has been previously suggested. Specifically, Nox4 downregulation using an siRNA approach attenuated lipopolysaccharide (LPS)-induced proinflammatory responses in human endothelial cells (204). Furthermore, uncoupling of eNOS was found to be intact in diabetic Nox2 KO mice (283). PKC-dependent activation of NOX4-derived ROS in endothelial cells in response to high glucose was also reported (66, 118, 278). A novel mechanism linking calcium to NOX5drived ROS and ERK1/2 signaling, which is crucial for regulation of vascular function, has been identified in endothelial cells (180). Dysregulation of these processes could contribute to endothelial dysfunction and renal disease. However, the specific role for the recently described human isoform, NOX5, in endothelial cells in the context of diabetes needs further study.

Limitations on studies with regard to endothelial cells in the context of DN include lack of specific isolation of glomerular endothelial cells. Most studies relied largely on surrogate cell lines such as human umbilical vein endothelial cells (HUVECs) (127) and aortic endothelial cells (118). 
Endothelial cells are known to exhibit functional heterogeneity. Hyperglycemia-induced endothelial dysfunction is differentially regulated in endothelial cells from different parts of the vascular system. For instance, Karbach et al. demonstrated that HUVECs and EA.hy926 cells both represent cellular models for diabetic vascular complications such as increase in oxidative stress and dysfunctional NO signaling. However, these cell lines differ in their viability and superoxide production in hyperglycemic conditions (132). Wang et al. showed a disparity between the expression of growth factors and impaired angiogenesis between microvascular and aorta-specific endothelial cells (265). Furthermore, HUVECs and HRGECs have distinct biological properties and specific gene expression features in response to IL-1 $\beta$. HRGECs demonstrated higher permeability and reduced expression of VE-cadherin. Moreover, glomerular endothelial cells remain to be fully characterized in diabetic and nondiabetic conditions. Thus, studies on endothelial dysfunction in diabetic renal disease perspective require more specific cellular or animal models.

\section{NOX-Mediated Podocyte Injury, Apoptosis, and Albuminuria}

While the earliest clinically detectable abnormality in DN is microalbuminuria that eventually progresses to proteinuria, very little is known about the cellular events that precede the onset of clinical albuminuria. The degree of proteinuria correlates with the progression of glomerulosclerosis and tubulointerstitial fibrosis of kidney. While glomerular hypertrophy, matrix accumulation, mesangial expansion, and GBM thickening are classical features of diabetic glomerular lesions, several preclinical and clinical evidences suggest that the onset of albuminuria is closely associated with podocyte injury, which includes foot process effacement, podocyte detachment, and depletion, as well as glomerular endothelial cell dysfunction (122). Podocyte apoptosis is an early glomerular phenotype in DKD that contributes to progressive depletion of podocytes and subsequent excretion of albumin in urine (245). Numerous studies have reported that excess levels of ROS induce podocyte apoptosis in a diabetic animal in vivo or in response to high glucose in vitro $(96,137)$. Indeed, NOX was found to be involved in podocyte depletion (74) and apoptosis through proapoptotic mediators, including p38 MAPK and caspase 3 in type 1 and 2 diabetic mice (245). In addition to hyperglycemia, other diabetes-related stimuli such as TGF- $\beta$ and AngII have been found to be associated with podocyte injury and apoptosis via excess production of ROS causing cellular dysfunction leading to increased excretion of albumin in the urine $(74,225,245)$. Podocyte injury has also been found to contribute to ECM accumulation and glomerulosclerosis in diabetes $(65,225)$. An increase in TGF- $\beta$ can stimulate ECM synthesis by the podocyte itself in an autocrine manner or may reach mesangial cells to induce a sclerosing phenotype in these cells. In addition, AGEs and their receptor RAGE via induction of TGF- $\beta$ have also been found to induce podocyte injury and apoptosis (271). It was also reported that systemic administration of a nonspecific NOX inhibitor, apocynin, prevented podocyte apoptosis and ameliorated urinary albumin excretion in diabetic mice $(7,245)$. Furthermore; high glucose stimulates hypertrophy of podocytes through ROS-dependent activation of ERK1/2 and Akt/PKB pathways $(96,137)$.
In the study by Durvasula (72), exposure of podocytes to high glucose resulted in increase in expression of AngII via elevation in renin activity and AT1R expression. In addition, exposure of podocytes to AngII has been found to upregulate expression of Nox4, Nox2, Rac, and p22phox $(21,190,268)$.

\section{NOX4}

Numerous experimental studies demonstrate the deleterious effect of NOX4-derived ROS in podocyte injury, leading to albuminuria, foot process effacement, and loss of podocytes in DKD $(74,75,125,124,135)$ (Fig. 5). We and others have shown enhanced ROS production through upregulation of Nox 4 in podocytes in response to high glucose and TGF- $\beta$ (74, $96,124,137,212,229)$. TGF- $\beta$ /Nox4-derived ROS mediates activation of caspase 3 via the Smad2/3 pathway leading to mouse podocyte apoptosis (56). In another study, highglucose-induced apoptosis of podocytes was found to be mediated via sequential upregulation of Nox 1 and Nox 4 by cytochrome P450 of the 4A family (CYP4A) (74). Nox4 was also shown to promote podocyte cell death by activating $\mathrm{p53-}$ upregulated modulator of apoptosis (PUMA)-dependent apoptotic pathways (73). Similar to mesangial cells, AMPK inhibits the mTORC1 pathway and was found to reduce NOX4-derived ROS in OVE26 type 1 diabetic mice, as well as in cultured podocytes exposed to high glucose (75). In addition, previously, we have shown that silencing of Nox4 in human podocytes in response to high glucose attenuated a range of inflammatory and fibrotic markers via reduction in ROS formation (124). A correlation between albuminuria and podocyte damage in diabetes has been documented by several studies. Previously, we have shown that global genetic deletion of Nox4 in ApoE KO and C57/BL6 STZ diabetic mice attenuated albuminuria and glomerulosclerosis (90). In addition, You et al. have shown that podocyte-specific induction of Nox4 in mice induces renal pathology, including glomerular hypertrophy, mesangial matrix accumulation, and GBM thickening, as well as albuminuria and loss of podocytes (282). More recently, we have demonstrated that deletion of Nox4 only in podocytes attenuates the diabetes-induced increase in albuminuria by $\sim 50 \%$ in diabetic mice (125). This finding strongly supports the view that NOX4-derived ROS in the podocyte play a significant role in the regulation of albuminuria in diabetes. Decreased expression of nephrin in diabetic mice has been found to be associated with GBM thickening, podocyte foot process effacement, broadening of slit pore, podocyte detachment, and depletion in number of podocytes in correlation with albuminuria $(51,68,176)$. Indeed, we have shown that Nox4 deletion in podocytes preserved nephrin expression and protected from ultraglomerular structural damage, including foot process effacement (125).The effect of NOX-derived ROS formation on VEGF expression, a growth factor expressed by renal cells, including podocytes associated with increased vascular permeability to macromolecules and albuminuria in diabetes, has been confirmed by various experimental studies $(52,244,251)$. Indeed, both global and podocyte-specific NOX4 deletions were found to be associated with decreased renal VEGF expression in diabetic mice. In addition, we and others have shown increased expression of $V E G F$ in podocytes in response to high glucose and silencing of Nox4-attenuated VEGF expression (124, 244, 251). Furthermore, a recent report suggested that blockade of VEGF 
signaling by a receptor kinase inhibitor ameliorates diabetic albuminuria in $\mathrm{db} / \mathrm{db}$ mice (244). These findings strengthen the postulate that NOX4-derived ROS play a crucial role in the modulation and regulation of $V E G F$ expression in podocytes. It has been demonstrated that acute hyperglycemia increases nephrin and endocytosis in a PKC- $\alpha$-dependent manner (215) and this effect is considered to promote albuminuria. Indeed, we have shown a direct link between diabetes-induced PKC activation and NOX4-derived ROS production in the podocytes in association with albuminuria $(125,251)$.

There is a close connection between diabetes and renal inflammation in DKD. Indeed, NOX4 deletion has been found to reduce macrophage infiltration and decrease expression of the key proinflammatory transcription factor $N F$ $\kappa B$ and the chemokine $M C P-1$ in renal cortex. In addition, high-glucose-induced upregulation of $N F-\kappa B$ and $M C P-1$ in podocytes was found to be attenuated by Nox4 silencing (124). Furthermore, the diabetes-induced increase in glomerular MCP-1 expression attenuated in podocyte-specific NOX4-deficient diabetic mice. This indicates that targeting NOX4 in podocytes not only prevents podocytopathy but may also play a key role in attenuating intrarenal inflammation. It is apparent from these studies that NOX4-derived ROS mediate podocyte damage, albuminuria, and ultimately other markers of renal injury.

\section{NOX5}

While the evidence for a role of NOX4 mediating podocyte injury and apoptosis in association with albuminuria in diabetes is clear, the role of NOX5 in podocyte dysfunction is currently getting more attention. A recent study by Holterman et al. found increased expression of NOX5 protein in human kidney material from diabetic patients (114). They reported that AngII stimulates NOX5-dependent ROS production in human podocytes and in conditionally immortalized mouse podocytes transfected with adenovirus-expressing Nox5 (Fig. 5). De novo human Nox 5 expression in mouse podocytes induced actin cytoskeleton rearrangement and Rac1 activation, which led to increased cellular motility. The increased cellular motility was thought to be comparable with podocyte foot process effacement associated with development of albuminuria (175). This study also found that ROS generated by NOX5 is additive when podocytes are costimulated with high glucose combined with AngII. The role of NOX5 in triggering podocyte damage was confirmed in vivo using podocytespecific Nox 5 transgenic mice. Transgenic mice expressing Nox 5 in a podocyte-specific manner (Nox5pod+) exhibited renal dysfunction, including early onset of albuminuria and podocyte foot process effacement (114). These findings support our own observations (unpublished data) that exposure of human podocytes to high glucose increases the expression of Nox 5 and silencing of Nox 5 resulted in attenuation of markers of fibrosis (collagen IV, fibronectin) and inflammation (MCP-1) via reduction in ROS formation. The relative contribution of individual isoforms, NOX4 and NOX5, in podocyte injury needs further investigation.

\section{NOX1}

Based on published data, it is unlikely that NOX1 plays an important role in podocyte dysfunction. Instead, our own data suggest that Nox1 deletion in ApoE KO diabetic mice did not attenuate albuminuria (124). This could be because of the low expression of Nox1 in the kidney, specifically in the podocyte. However, mTORC1-derived increased expression of NOX1 protein was reported in cultured podocytes in response to high glucose (75).

\section{NOX2}

The involvement of NOX2 in the development of albuminuria remains unclear. It was reported that insulin-deficient diabetic Nox $2 \mathrm{KO}$ mice, despite a reduction in macrophage infiltration, did not demonstrate reduced albuminuria as well as glomerular ECM accumulation and tubulointerstitial fibrosis, suggesting that this lack of renoprotection may be due to upregulation of renal Nox4 (284). However, a recent study has shown that administration of antioxidant, probucol, was associated with attenuation of albuminuria, ECM protein collagen IV accumulation, and podocyte damage via inhibition of NOX2 expression. In addition, another recent study examining a mouse model of fibrosis demonstrated that p47phox KO mouse attenuated albuminuria and glomerulosclerosis via reduction in ROS (263).

\section{NOX-Mediated Tubulointerstitial Injury in DKD}

Not only glomerular cells but also renal tubular cells are adversely affected by diabetes. Changes in podocytes, which participate in the initiation of glomerulosclerosis and leakage of plasma proteins, and tubulointerstitial fibrosis are other key events in the progression of DKD. It is believed that downstream of the glomeruli, exposure of plasma proteins in association with chronic hyperglycemia across the tubular compartment of the nephron can trigger profibrotic and proinflammatory mechanisms in tubular epithelial cells, thereby inducing the development of tubulointerstitial fibrosis (200). Tubulointerstitial fibrosis is characterized by accumulation of interstitial fibroblasts and excessive ECM deposition in the tubulointerstitial space (119), ultimately leading to disrupted tubular reabsorption. The proximal tubular epithelial cells are considered to be major players in orchestrating renal interstitial fibrosis in DN (172). Similar to glomerular injury, NOX-derived ROS are involved in the process of tubulointerstitial fibrosis in diabetes (Fig. 6). Indeed, inhibition of NOX activity by apocynin was found to result in reduction in renal gluconeogenesis via activation of the ERK1/2 pathway in rat proximal tubules exposed to high glucose as well as in Zucker diabetic fatty rats (270), suggesting the implication of NOX-derived ROS in renal glucose regulation. In addition, NOX-dependent ROS in renal tubular cells in response to high glucose is found to be associated with stimulation of MAPKs and the redox-sensitive transcription factor, NF- $\kappa \mathrm{B}$, leading to upregulation of the proinflammatory gene $M C P-1$ (276). One of the potential mechanisms for renal fibrosis is epithelial-mesenchymal transition (EMT), in which there is a transdifferentiation of epithelial cells into motile mesenchymal cells (16). Hyperglycemia along with TGF- $\beta$, AngII, CTGF, albumin, and AGEs induces EMT in renal tubular cells with upregulation of alpha-smooth muscle actin ( $\alpha$-SMA) and vimentin and downregulation of E-cadherin $(34,40,154,275)$.

\section{NOX4}

There is experimental evidence to suggest that the expression of Nox 4 in the tubular epithelium, particularly in the 
proximal tubule, is predominantly comparable with other renal cells in diabetes (Fig. 6). Indeed, expression of NOX4 protein and ROS production were found to be increased in the kidneys of diabetic mice and NOX4 expression was largely localized to the tubules (229). Increased protein levels of NOX4, but not of NOX1, NOX2, p22phox, or p47phox, were found in mouse proximal tubules in response to high glucose $(80,229)$. NOX4-derived ROS formation in mouse proximal tubules exposed to high glucose activates profibrotic processes via NOX4-sensitive p38 MAPK-dependent pathways $(80,229)$. Excessive deposition of ECM in the tubulointerstitium has a significant impact on the progressive decline in renal function in chronic kidney disease. Indeed, NOX4dependent ROS production and subsequent Akt phosphorylation resulted in accumulation of fibronectin in proximal tubular epithelial cells in response to high glucose (187). The view that NOX4 is the major source of ROS in the tubular compartment of the diabetic kidney has been supported by our own study demonstrating that genetic deletion of Nox4 in ApoE KO or in C57/BL6 diabetic mice markedly reduced ROS production in renal cortex, which mainly comprises tubular epithelial cells $(124,251)$. In contrast, this effect was not seen upon Nox 1 deletion in the renal cortex of diabetic ApoE KO mice. TGF- $\beta$ is a known profibrotic growth factor mediating tubular injury via interaction of TGF- $\beta$ with NOX4. Lee et al. have shown that NOX4-mediated ROS generation in the tubular cells in response to TGF- $\beta$ was ameliorated by activation of the AMPK pathway (154). In addition, inhibition of NOX4 by plumbagin (a nonspecific NOX4 inhibitor) or silencing of Nox 4 attenuated expression of fibronectin and collagen IV in human proximal tubular cells exposed to high glucose and TGF- $\beta$ (280). Contribution of the matrix metalloprotease (ADAM)-17 in matrix accumulation and renal fibrosis has been suggested in diabetes. Increased expression and activity of ADAM17 in association with upregulation of Nox 4 were observed in mouse proximal tubular cells in a high-glucose environment. Interestingly, inhibition of ADAM17 resulted in attenuation of ROS production and fibrosis in diabetic OVE26 mice via downregulation of Nox4, suggesting a role in Nox4-mediated oxidative stress and kidney injury (85).

Another growth factor contributing to ECM protein accumulation in DKD is insulin-like growth factor-I (IGF-I). IGF-I was found to accelerate the fibrotic process via NOX4-derived ROS and activation of Akt/PKB and mTOR/p $70^{\mathrm{S} 6 \mathrm{~K}}$ signaling pathways in renal tubular epithelial cells (187). Similar to the glomeruli, both PKC- $\alpha$ and PKC- $\beta$ in association with NOX4 contribute to tubulointerstitial fibrosis in diabetes $(194,251)$. Furthermore, a recent study has found that chronic exposure of albumin to renal tubular cells induces inflammation through the HSP70-TLR4 axis in mice with early DN (126). Interestingly, in response to glycated albumin, an early stage glycation product, rat tubular epithelial cells demonstrated accelerated fibrosis and apoptosis and silencing of Nox 4 ameliorated these changes (214). A recent study by He et al. (110) demonstrated that high-glucose-induced EMT is attenuated by decreasing intracellular ROS levels via downregulation of Nox1 and Nox4, but not of Nox2, and thereby activating the ERK signaling pathway in human tubular epithelial cells. It was also reported that the inhibitory effect of AMPK on TGF- $\beta$, AngII, and high-glucose-induced EMT was mediated by suppression of Nox4 expression (158). TGF- $\beta$ seems to play a critical role in myofibroblast differentiation via activation of Smad2/3, Akt/ $\mathrm{PKB}$, and ERK signaling pathways $(8,169)$. In addition, the TGF- $\beta / \mathrm{Smad} 2 / 3$ cascade is tightly regulated by the activation of MAPK in mesangial cells and fibroblasts (285). Rhyu et al. found that NOX-dependent ROS is integral in activation of TGF- $\beta /$ Smad $2 / 3$ pathways in proximal tubular epithelial cells (217). Another study using renal interstitial fibroblasts demonstrated that TGF- $\beta / \mathrm{NOX} 4$-induced ROS generation contributes to myofibroblast differentiation to a profibrotic phenotype via activation of Smad 3 and ERK pathways (24). A recent study by Manickam et al. has shown that TGF- $\beta$-induced kidney fibroblast differentiation to a myofibroblast is mediated by Rho/Rho-associated protein kinase (ROCK) via activation of NOX4 (165). Furthermore, stimulation of renal tubular epithelial cells with AngII was shown to induce apoptosis and EMT via NOX4-dependent ROS production and resultant Src/ caveolin-mediated activation of the epidermal growth factor receptor/ERK signaling pathway (40, 138, 207, 276).

\section{NOX5}

Emerging evidence suggests a contribution of NOX5derived ROS in tubulointerstitial fibrosis. A recent study by Holterman et al. showed early tubulointerstitial fibrosis in podocyte-expressing Nox 5 mice even in the absence of diabetes. This was further accelerated in the presence of diabetes (114). In another study, albeit in the hypertensive context, $\mathrm{Yu}$ et al. have demonstrated that Nox 5 expression is predominantly increased in human proximal tubules obtained from hypertensive subjects and showed increased ROS formation compared with proximal tubules of normotensive individuals. In addition, silencing of Nox 5 in hypertensive cells reduces ROS production and fibrosis (284).

\section{NOX2 and NOX1}

The importance of NOX2 in mediating tubular injury in diabetes is controversial. Increased expression of Nox 2 in the renal cortex was shown in insulin-deficient diabetic rats (96), but the expression of Nox 2 and p47phox was not affected in type 2 diabetic mice (229). In addition, You et al. (281) demonstrated that Nox $2 \mathrm{KO}$ mice did not attenuate tubulointerstitial injury in insulin-deficient diabetes. The importance of NOX1 is largely unknown in tubulointerstitial fibrosis, including in diabetes. From these findings, it is apparent that NOX4 and more recently NOX5-derived ROS seem to have predominant implications in the molecular mechanisms underlying fibrosis in DN.

\section{NOX-Mediated Tubular Reabsorption Dysfunction in DKD}

Diabetes is associated with renal $\mathrm{Na}^{+}$retention and expanded extracellular fluid volume. Volume expansion is largely responsible for hypertension in diabetes and contributes to the altered renal hemodynamics. The increased urinary albumin excretion is not only due to leakage from the altered glomerular compartment but also due to a decrease in albumin reabsorption by the proximal tubule (200).The precise molecular mechanisms underlying the increase in $\mathrm{Na}^{+}$ retention and proteinuria remain unresolved. However, NOX-derived ROS is proposed to be involved in this pathological process. 


\section{NHE3}

Reabsorption of salt and water in proximal tubules mainly occurs by the $\mathrm{Na}^{+} / \mathrm{H}^{+}$exchanger isoform 3 (NHE3). In addition, NHE3 also plays a role in receptor-mediated albumin uptake in the proximal tubule. Hyperglycemia and AngIImediated activation of NOX and subsequent increased ROS production activate NHE3 activity in the proximal tubules in diabetes leading to alteration in tubular $\mathrm{Na}^{+}$transport (116, 143). This effect was evident by decreased $\mathrm{Li}+$ clearance, a marker of proximal tubular reabsorption after NOX inhibition (210). Importantly, NOX-mediated superoxide was found to modulate the activity of NHE3 in proximal tubules in diabetes (210). These findings suggest that aberrant activity of proximal tubular NHE3 and albumin uptake may confer renal salt/water retention and increased excretion of protein in DKD.

\section{SGLT2}

The bulk of glucose filtered by the glomerulus is reabsorbed in the early proximal tubule by the sodium glucose cotransporter, SGLT2, which is expressed mainly on the apical membrane of renal proximal tubules, whereas SGLT1 removes the remaining luminal glucose in the distal proximal tubule (259). Glycosuria can be observed in diabetes; however, glucose reabsorption by SGLT2 is enhanced under diabetic conditions. Oxidative stress regulates the activity of SGLT2, with selective inhibition of SGLT2 that increases glycosuria in diabetes. Interestingly, insulin stimulates SGLT-2-mediated glucose entry into cultured proximal tubular cells via oxidative stress (185). The involvement of NOX-derived ROS in SGLT2-mediated glucose reabsorption remains to be evaluated. Increased levels of ROS formation in proximal tubules in response to high glucose have been shown to be mediated through AngII and subsequent activation of the NOX system; therefore, it is hypothesized that high glucose and AngII regulate renal SGLT2 via NOX, particularly NOX4.

\section{NOX-Derived Markers of Oxidative Stress in Urine}

Several preclinical and clinical studies have identified the presence of a range of oxidative stress markers in the urine of diabetic individuals or diabetic animals with nephropathy, including proteinuria and loss of podocytes $(137,179,251)$. These urinary oxidative stress markers include 8-oxo-7,8dihydro-2-deoxyguanosine $(8-\mathrm{OHdG})$, which is a product of oxidative DNA damage and F2 isoprostane 8-iso prostaglandin F2 (8-iso PGF2), which is a widely recognized marker of lipid peroxidation in patients with diabetes. In addition, our own studies have shown that activation of NOX, particularly NOX4-derived ROS, contributes to the generation and subsequent excretion of these oxidative stress markers in the urine of diabetic animals $(125,251)$.

\section{NOX and Therapeutic Perspectives for DKD}

Numerous clinical studies have shown that antioxidant therapies failed to improve the health of patients with cardiovascular and DKD. This is partly because of the lack of information about the specificity and the mechanism of action of these antioxidants. This raises many questions in relation to our current knowledge of the molecular processes involved in ROS formation. The use of dietary antioxidant supplements and selective inhibitors of various enzymatic sources of ROS, including NOX inhibitors, has been employed to combat oxidative damage of tissue (195). NOX has been shown to be a potential target for pharmacological intervention in DKD. In this section, we will update the information about both NOXspecific inhibitors and nonspecific antioxidants that have been tested in diabetes (Fig. 7).

\section{NOX-Specific Inhibitors}

\section{GKT}

The new advancement in ROS/NOX biology has shown some degree of progress in developing NOX-specific agents. Some of these compounds, considered NOXspecific inhibitors, have shown promising results at the preclinical level. Recently, pyrazolopyridine compounds, NOX-specific agents named GKT136901 and GKT137831, have been developed by Genkotex (www.genkyotex.com/). Both GKT136901 and GKT137831 are not only dual inhibitors for the NOX1 and NOX4 isoforms and are reported

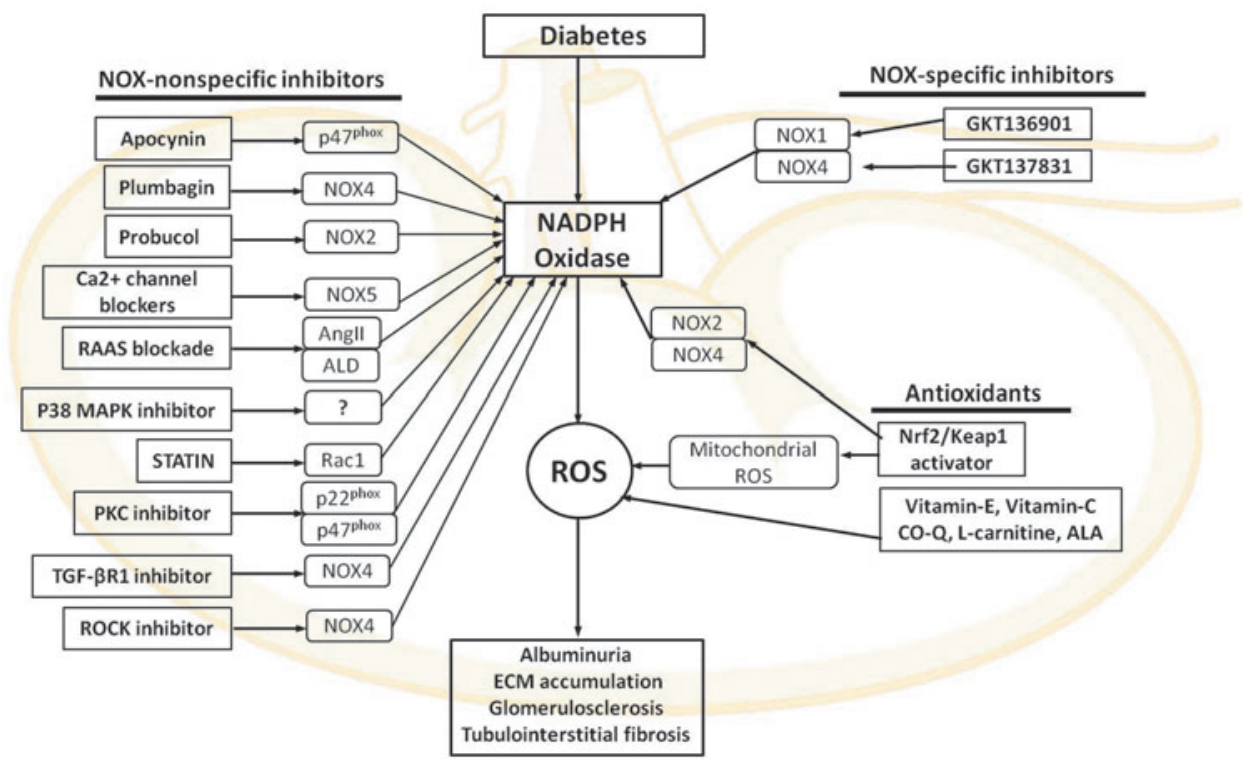

FIG. 7. Agents targeting NOXs in DKD. ALA, $\alpha$-lipoic acid; ALD, aldosterone; CO-Q, coenzyme Q; Keap1, Kelchlike ECH-associated protein 1; Nrf2, NFE2-related factor 2; TGF- $\beta \mathrm{R} 1$, transforming growth factor receptor 1 . To see this illustration in color, the reader is referred to the web version of this article at www.liebertpub .com/ars 
to inhibit NOX1/NOX4-derived ROS production but they also confer a certain degree of inhibitory action on NOX5 and an almost negligible effect on $\operatorname{NOX} 2(6,89,151,229)$. However, the inhibitory mechanism of action of these compounds is not fully delineated. Both inhibitors have structural resemblance with NADPH and hence they may act as competitive inhibitors. Treatment with GKT136901 was shown to attenuate ROS generation in response to high glucose in mouse proximal tubular cells via reduction in NOX activity (229). Administration of GKT136901 in a mouse model of type 2 diabetes was found to attenuate albuminuria and ROS production possibly via decreased ERK1/2 activation (230). In addition, we and others have tested the effect of another series of NOX1/NOX4specific inhibitors, GKT137831, in animal models of insulindeficient DN (STZ -ApoE KO and OV26) mice and have shown renoprotective effect of this compound with attenuation of albuminuria and preserved renal structure in association with reduced renal ROS formation $(97,124)$. Furthermore, a recent study by You et al. has shown renoprotective effects with GKT137831 in a podocyte-specific Nox4-overexpressing Akita mouse model of DKD (282). Moreover, administration of GKT137831 attenuated ischemic-induced inflammation in the retina and neuroglia of rats (62). With the support of these preclinical data, GKT137831 has completed phase I safety trials. Furthermore, recently, a phase IIb clinical study in type 2 DN has been completed, which did not show attenuation of albuminuria, but a significant reduction in markers of inflammation and ROS (www.genkyotex.com/genkyotex/index.cfm/ news-events/genkyotex-announces-top-line-results-of-phase2-clinical-program/).

The expression of NOX isoforms varies in different tissues with NOX4 predominantly expressed in the kidney, whereas NOX1 is more widely expressed in the macrovasculature. Treatment of diabetic ApoE ${ }^{-/-}$mice with GKT137831 attenuated not only renal disease but also atherosclerosis in shortand long-term studies, suggesting that concomitant NOX1 and NOX4 inhibition can provide simultaneous athero- and renoprotection. Considering the presence of NOX5 in patients, the role of NOX5 requires further studies. Isoform-specific NOX inhibitors are currently being developed and it needs to be shown if isoform-specific NOX inhibitors will provide superior protection in individual organs or if combined inhibitors such as GKT137831 are superior because of simultaneous protection of several organs.

\section{NOX Nonspecific Inhibitors}

\section{Apocynin}

Initially, apocynin was presented as a pharmacological inhibitor of NOX. Administration of apocynin to STZinduced diabetic rats resulted in a decrease in plasma lipid peroxidation products, renal $\mathrm{H}_{2} \mathrm{O}_{2}$ production, and urinary protein excretion via inhibiting the translocation of $\mathrm{p} 47 \mathrm{phox}$ from the cytosol to plasma membranes in the kidney (7). In addition, another report suggested that apocynin attenuated albuminuria and prevented podocyte apoptosis, podocyte depletion, and mesangial matrix expansion in $\mathrm{db} / \mathrm{db}$ diabetic mice (245). However, recently, it was reported that apocynin is not a specific inhibitor of NOXs, but rather a nonspecific antioxidant. In HEK293 cells overexpressing Nox1, Nox2, or Nox4, apocynin failed to inhibit superoxide generation detected by lucigenin chemiluminescence (112). Furthermore, another study has also suggested that apocynin does not inhibit vascular NADPH oxidase-dependent superoxide formation, but rather may have alternative or additional actions, including inhibiting Rho kinase activity (226).

\section{Plumbagin}

Plumbagin is a plant-derived compound and has been considered to be an Nox4 inhibitor. Plumbagin has shown antiatherosclerotic and renoprotective effects in diabetic animals (67). Administration of plumbagin attenuated albuminuria, accumulation of ECM proteins, and ROS production via downregulation of Nox4 in a mouse model of DKD (280). However, the mechanism of action and specificity toward NOX4 remain questionable. Further studies are needed to fully characterize the specific action of these drugs on NOX activity in human DN.

\section{GLX351322}

Recently, another agent called GLX351322 presented as a specific NOX4 inhibitor has shown to counteract glucose intolerance in high-fat diet-treated C57BL/6 mice (5). However, the compound specificity toward NOX4 remains to be fully evaluated.

\section{Probucol}

The antioxidant, probucol (a clinically used lipid-lowering drug), has reported to possess cardioprotective effects in experimental models of heart failure via its antioxidant properties and an enhancement of endogenous antioxidant reserve (76). Recently, it was demonstrated that probucol inhibits NOX2 expression and attenuates podocyte injury and albuminuria in a type 2 diabetes mouse model of nephropathy (291). The calcium-dependent NOX, NOX5, is recognized to be an important source of ROS in atherosclerosis and hypertension, as well as in DKD $(107,114)$. Administration of calcium channel blockers significantly reduced albuminuria levels in patients with DN (256). Currently, there is no direct evidence suggesting a direct effect of $\mathrm{Ca}^{2+}$ channel blockade on NOX5 inhibition.

\section{RAAS blockade}

ACE inhibitors and Ang-II AT1 receptor blockers are currently employed to delay the decline of renal function in DKD. ACE inhibitors and ARB suppress renal ROS production and $\mathrm{p} 47^{\text {phox }}$ expression in association with attenuation of microalbuminuria in STZ-induced diabetic rats (196). The inhibition of NOX downstream of RAS may offer a novel approach to delay the onset of renal dysfunction. In addition, administration of eplerenone, an aldosterone inhibitor, to diabetic animals with obesity, hypercholesterolemia, and hypertension was found to be associated with attenuation of albuminuria and renal ROS production via reducing NOX activity (183).

\section{p38 MAPK inhibitor}

It has been reported that p38 MAPK is increased in the kidney of Dahl salt-sensitive hypertensive rats. A specific inhibitor of p38 MAPK, FR-167653, blocked phosphorylation of p38 MAPK and reduced NOX activity and superoxide production in the kidney, resulting in reduction of proteinuria and glomerulosclerosis (255). In experimental animal models 
and diabetic patients, renal p38 MAPK is increased and has been suggested to enhance early hypertrophy and ECM accumulation (130); therefore, p38 MAPK inhibition may represent an alternative strategy against DN.

\section{Statins}

Several reports have demonstrated beneficial effects of inhibitors of 3-hydroxy-3-methylglutaryl coenzyme A reductase, the so-called statins, in DN. Besides their cholesterollowering effect, statins suppress membrane translocation of Rac and inhibit NOX stability on the plasma membrane (254). In $\mathrm{db} / \mathrm{db}$ mice with type 2 diabetes, treatment with pitavastatin ameliorates albuminuria and mesangial expansion by minimizing oxidative stress via downregulation of NOX4 expression in the kidney (87). Thus, it is possible that statins could improve DN via their effects on NOX4. In addition, other drugs used in diabetes and hyperlipidemia, including gliclazide and fibrates, also inhibit NOX and reduce oxidative stress, but further studies are necessary to assess the direct renoprotective effect of these agents.

\section{Inhibitor of PKC}

Both PKC- $\alpha$ and PKC- $\beta$ play an important role in diabetic renal pathology via activation of NOX. A recent study has demonstrated that a conventional PKC (PKC- $\alpha$ and PKC- $\beta$ ) inhibitor, Gö6976, suppresses increased expression of $\mathrm{p} 22^{\text {phox }}, \mathrm{p} 47^{\text {phox }}$, and collagen IV, along with reduced ROS production in mesangial cells under high-glucose conditions (274). Despite these promising observations, it must be noted that PKC has many roles in the phosphorylation of multiple proteins that control cell permeability, gene transcription, and other cellular responses. Thus, inhibitors of PKC activity are not specific for NOX and could have off-target effects if used systemically.

\section{Inhibitors of TGF- $\beta R 1$}

TGF- $\beta$ is well recognized to regulate the expression of Nox 4 in various renal cells in response to glucose. Silencing of Nox4 in kidney myofibroblasts inhibited TGF- $\beta$-induced stimulation of NOX activity, and inhibition of TGF- $\beta$ R1 blocked Smad3 phosphorylation, reduced enhanced NOX activity, and decreased expression of Nox4 (24). In a recent study, it was demonstrated that administration of soluble human TGF- $\beta$ type II receptor (sT_RII.Fc) provided renoprotective effects by reducing fibrosis and albuminuria through neutralizing TGF- $\beta$ (223). However, the systemic administration of TGF- $\beta$ blockers is not feasible for the treatment of DN because of the immunoprotective effect of TGF- $\beta$. On the other hand, blocking of TGF- $\beta$ may have important hemodynamic effects, which are relevant to diabetic complications (173).

\section{ROCK inhibitor}

Recently, it has been reported that treatment with Fasudil, a specific ROCK inhibitor in diabetic rats, significantly reduced albuminuria and decreased levels of urinary 8hydroxyguanosine, a marker of oxidative stress (94). This finding was supported by another study, in which the administration of an ROCK inhibitor to $\mathrm{db} / \mathrm{db}$ mice, a model of type 2 diabetes, was associated with decreased albuminuria, mesangial expansion, accumulation of glomerular type IV collagen, and GBM thickening via downregulation of TGF- $\beta$ and NOX4 (144). However, these findings lack specificity toward Nox4.

\section{Endogenous and Dietary Antioxidants}

\section{Keap1-Nrf2 pathway}

Endogenous antioxidants play an important role in combating oxidative stress in various diseases, including DKD. The transcription factor NFE2-related factor 2 (Nrf2) is considered a regulator of cellular detoxification responses and redox status. Nrf2 in combination with its negative regulator, Kelch-like ECH-associated protein 1 (Keap1), activates the antioxidant response element, leading to increased expression and activity of several antioxidants, including glutathione S-transferase, hemeoxigenase-1, and $\gamma$-glutamylcysteine synthetase, and NADPH quinone oxidoreductase $(133,134)$. Indeed, a recent study has suggested that the Keap1-Nrf2 pathway regulates both mitochondrial and cytosolic ROS production through NOX (146). Nrf2 was found to be upregulated in response to hyperglycemia in the kidney and specifically in certain renal cells (290). Nrf2 activators, such as sulforaphane or cinnamic aldehyde, were shown to attenuate damage and preserve renal function in diabetic mice, indicating that Nrf2 might be a valuable therapeutic target in DN (290). In addition, experimental evidence suggests that Nrf2 $\mathrm{KO}$ mice or silencing of Nrf2 in renal cells aggravates accumulation of matrix proteins in diabetes (59). Bardoxolone methyl, an Nrf2 activator has anti-inflammatory effects, and after an initial promising clinical trial study known as the BEAM trial in patients with DN, the subsequent phase 3 trial was prematurely terminated (BEACON; Bardoxolone Methyl Evaluation in Patients With Chronic Kidney Disease and Type 2 Diabetes) because of higher cardiovascular mortality in the treated group (ClinicalTrials.gov NCT01351675) (208, 209). In addition, several trials using dietary antioxidant supplements containing vitamins (e.g., vitamin E, vitamin $\mathrm{C}$, coenzyme Q10, L-carnitine, $\alpha$-lipoic acid) have been conducted to combat oxidative stress-induced tissue damage in diabetes; however, a meta-analysis on 14 studies on type 2 diabetic individuals showed that many of the trials failed to improve the disease outcome (4) and some had deleterious effects. Hence, one has to be cautious with the use of these dietary antioxidants as their mechanism of action and function remains poorly understood.

\section{Mitochondrial ROS in DKD}

Growing number of evidences suggest that mitochondrial respiratory chain-derived ROS are crucial mediators in the progression of DKD (53). It is unknown whether mitochondrial deregulation is a cause or consequence of renal dysfunction, but it appears to be part of a vicious cycle perpetuating ROS generation and end-organ injury. Under normal physiological conditions, mitochondria generate substantial amounts of superoxide caused by electron leakage from the oxidative phosphorylation pathway. However, in diabetes, excess glucose uptake by susceptible cells leads to more glucose-derived pyruvate being oxidized in the citric acid cycle in mitochondria that pushes more electron donors $\left(\mathrm{NADH}\right.$ and $\left.\mathrm{FADH}_{2}\right)$ into the electron transport chain causing electron leakage, resulting in overproduction of superoxide 
$(30,188)$. In addition, the hyperglycemic state impairs the activity of enzymes of the mitochondrial respiratory chain complex. As a result, a positive feedback loop of oxidative stress occurs over time leading to mitochondrial dysfunction, cell injury, and apoptosis. Current existing data demonstrate that mitochondrial ROS (mtROS) produced by increased flux through oxidative phosphorylation induce adverse effects in DN, including cell apoptosis, hypertrophy, mesangial matrix expansion, podocyte apoptosis, and inflammation $(111,245)$, as illustrated in Figure 8. Increased formation of mtROS in the kidney has been observed in experimental diabetes $(37,53$, $220,245)$. It is postulated that the excess mtROS is mediated by electron leakage at two main sites: complex I (NADH: ubiquinone oxidoreductase) and at the interface of complex III (ubiquionol:cytochrome c oxidoreductase) $(20,145,211)$. Indeed, mitochondria from renal cortex of diabetic rats demonstrated diminution of oxidative phosphorylation via a decrease in respiratory complex III activity and increased superoxide production (219). Moreover, opening of the mitochondrial permeability transition pore induced ROS production at the level of the respiratory chain complex I (17). In diabetes, the AGE-RAGE interaction induces $\mathrm{H}_{2} \mathrm{O}_{2}$ production, facilitating the induction of mitochondrial permeability transition and promoting complex I deficiency of the mitochondrial respiratory chain (53). Mitochondrial dysfunction is associated with reduced adenosine triphosphate (ATP) production. Indeed, decreased renal mitochondrial ATP production has been observed in the renal cortex of diabetic mice (248). Proximal tubular cells contain a large number of mitochondria owing to their many functional roles, including energetically active reabsorption of glucose from the urinary filtrate. Active transport is key to the reabsorptive processes in the proximal tubule. In diabetes, to maintain the glucose gradient, a greater pool of
ATP is demanded. Inability to deliver ATP-driven transport can lead to impairment of proximal tubular epithelial cells in diabetes. Indeed, ATP depletion in proximal tubular cells is associated with impaired solute and ion transport as well as with a disruption of the actin-based cytoskeleton and disturbances in the apical basolateral protein polarization and apoptosis (26).

A central role for mitochondrial dysfunction and oxidative stress in DKD involves fibrosis along with infiltration of inflammatory cells. This is supported by a number of studies demonstrating activation of fibrotic and inflammatory pathways in DKD by mtROS. Indeed, in glucose or AGE-stressed podocytes, mtROS activate the NLrp3 inflammasome, which has been shown to be induced in DKD $(232,292)$. Under conditions of cellular stress, Nlrp3 induces caspase-1mediated responses, including secretion of proinflammatory cytokines such as IL-1beta and IL-18 (162). Inhibition of mtROS prevented glomerular inflammasome activation and $\mathrm{DN}$ in mice. Moreover, Nlrp3 has been shown to be a crucial element of EMT of tubular epithelial cells, a process associated with tubular atrophy and interstitial fibrosis in chronic kidney disease (162). ROS activates a range of other pathways implicated in renal fibrosis. Inhibition of mitochondrial electron transfer chain complex I, rotenone, significantly blocked high-glucose-induced ROS generation in mesangial cells and high-glucose-driven fibronectin upregulation in tubular epithelial cells (156). Treatment with MitoQ (mitochondria-targeted ubiquinone) has been shown to improve tubular and glomerular function in insulin-deficient Akita mice. MitoQ treatment was associated with a decrease in nuclear accumulation of profibrotic transcription factors, phospho-Smad $2 / 3$ and beta-catenin, in Akita mice, indicating reduced TGF- $\beta /$ Smad signaling in these mice (37).

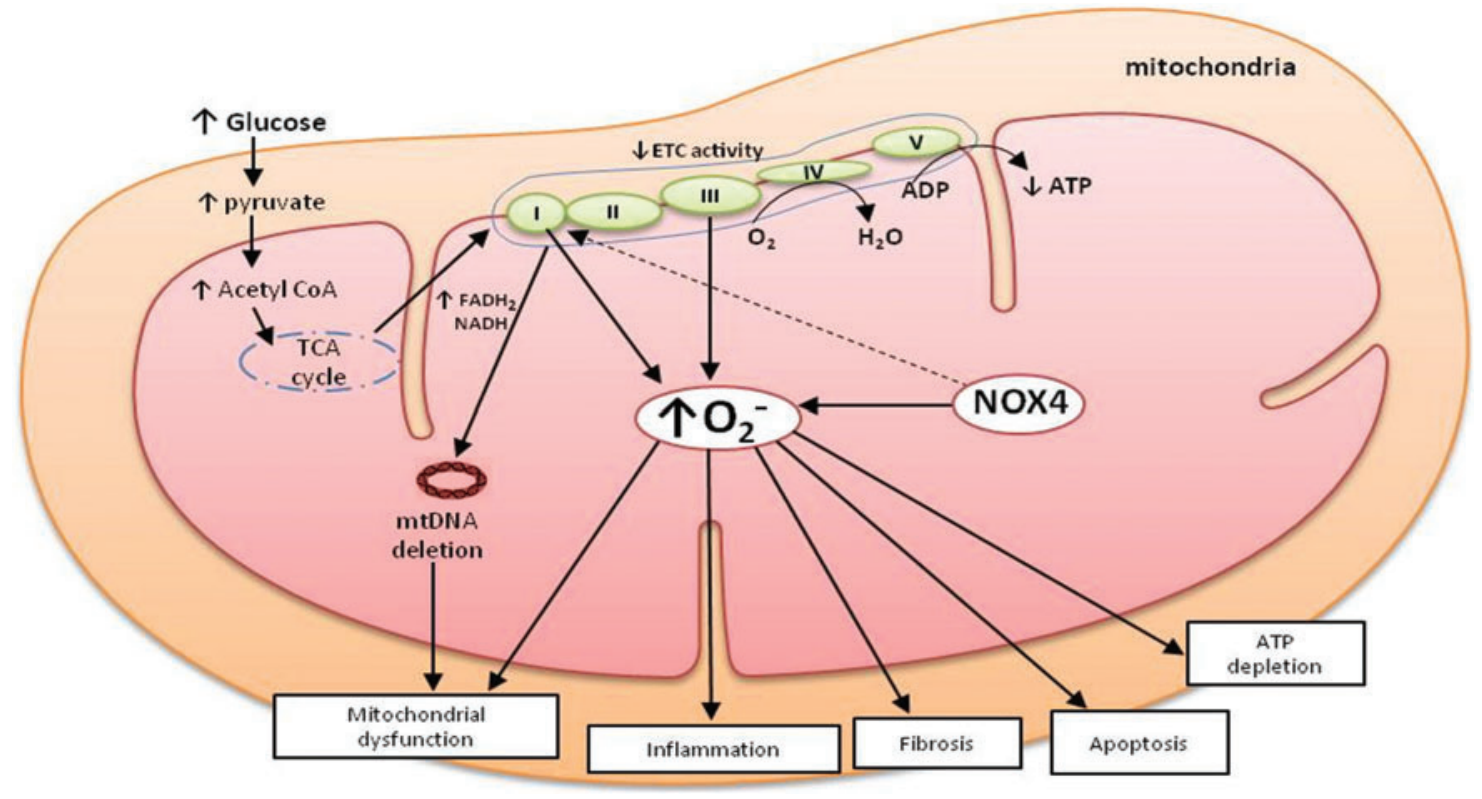

FIG. 8. Factors associated with mitochondrial dysfunction and ROS generation in DKD. Under hyperglycemic states, more glucose is oxidized, which pushes more NADPH and $\mathrm{FADH}_{2}$ into the electron transport chain and causes excess leakage of electrons forming superoxide. Acetyl CoA, acetyl coenzyme A; ATP, adenosine triphosphate; ETC, electron transport chain; FAD, flavin adenine dinucleotide; mtDNA, mitochondrial DNA; TCA, tricarboxylic acid cycle. To see this illustration in color, the reader is referred to the web version of this article at www.liebertpub.com/ars 
Whether the decreased mitochondrial function and content contribute to enhanced mtROS production and subsequent renal dysfunction in diabetes is unclear. This issue has been addressed by stimulating mitochondrial biogenesis through the AMPK pathway. AMPK is a ubiquitously expressed protein that plays a key role in energy homeostasis of the cell. It is highly expressed in the renal cells, including podocytes, mesangial cells, glomerular endothelial cells, and particularly in mitochondria-rich cells such as proximal tubular cells (150). In experimental models of diabetes, the activity of AMPK appears to be reduced in the kidney. In energydepleted conditions, intracellular concentrations of AMP rise, while levels of ATP fall. This leads to activation of AMPK and phosphorylation of substrates that promote catabolic processes to generate ATP. However, in excess energy states such as in diabetes, reduced AMPK activation stimulates protein synthesis and cell growth. In experimental models of diabetes, the activity of AMPK appears to be reduced in the kidney (141). However, two opposing models have been proposed with regard to the role of mtROS in reducing AMPK activation. One model upholds the current prevailing theory that in the diabetic kidney, there is increased mtROS, which leads to reduction of AMPK activity and decreased mitochondrial biogenesis (188).

However, opposite to the prevailing theory that mitochondrial overproduction of superoxide is the basis of DKD, the Dugan et al. study (69) reported reduced superoxide production in STZ diabetes mice, suggesting suppressed mitochondrial activity. In diabetic conditions or in conditions of caloric excess, the mitochondria consume fewer electrons and oxygen and consequently there is a reduction of carbon flow into the mitochondria (69). The authors attributed the reduced mitochondrial function in diabetes to reduced AMPK along with a decrease in pyruvate dehydrogenase activity and PGC1- $\alpha$ expression. This study suggested that increased AMPK activity would increase ROS production by mitochondria.

\section{NOX4-Mediated Mitochondrial Dysfunction}

It has been suggested that NOX4-mediated ROS production plays a role in mitochondrial dysfunction in various renal cell lineages, including mesangial cells, cardiac myocytes, and endothelial cells $(3,22,148)$. Indeed, a study by Block et al. suggested that NOX4 is localized in the mitochondria and is upregulated in response to high glucose and that silencing of Nox4 is associated with reduced mitochondrial oxidative stress and renal injury (22). Our own data suggested a reduction in ROS formation in both mitochondrial and cytosolic fractions of Nox4-deficient diabetic mice (124). A report by Das et al. (56) suggested that TGF- $\beta$ induces upregulation of mitochondrial Nox4, which increases the ROS burden, leading to mitochondrial depolarization and podocyte apoptosis. Moreover, AngII-induced mitochondrial NOX4-derived ROS in the mitochondrial fraction of renal tubular cells was found to be associated with mitochondrial dysfunction and apoptosis (138). In addition, Koziel et al. suggested that NOX4 inactivates mitochondrial respiratory chain complex I and thereby induces mitochondrial dysfunction in human endothelial cells (148). However, a recent study by Dugan et al. showed a reduction in mitochondrial superoxide levels in murine models of type 1 diabetes (69). One possibility could be that superoxide rapidly binds to NO to form peroxinitrite and, indeed in the same study, they found an increased level of nitrotyrosine in the kidney.

\section{Conclusion}

It has become apparent in recent years that oxidative stress is an important element initiating diabetic microvascular complications, including DKD. Renal oxidative stress in diabetes is the consequence of a series of pathological events causing an imbalance between the pro-oxidant levels and counteracting antioxidant defense mechanisms in response to chronic hyperglycemia. Despite advancement in the field of ROS pathobiology, so far, there are no therapeutic options to reduce directly oxidative stress in the progression of DKD. NOXs, particularly NOX4 and the more recently identified human isoform, NOX5, are important sources of ROS in the kidney. With ongoing technical difficulties in defining, at the protein and enzymatic levels, the status of the different NOX isoforms, it has been a challenge to characterize the relative importance of the contribution of the various NOX isoforms in individual renal cell populations. Currently, the strongest data are related to NOX4, which appears to be widely distributed within the kidney, particularly in tubules and podocytes. However, the role of other NOX isoforms particularly in immune infiltrating cells such as macrophages in the kidney warrants further exploration. The development of NOX4 or NOX5-specific pharmacological inhibitors will provide additional information about the role of ROS in the renal pathology in diabetes. Further studies are required for better understanding of the contribution of mtROS and antioxidant pathways such as the Nrf2-Keap-1 pathway in renal disease in diabetes.

\section{Acknowledgments}

This work was supported by the National Health and Medical Research Council of Australia and a JDRF Program/ Project Grant.

\section{References}

1. Ago T, Kitazono T, Ooboshi H, Iyama T, Han YH, Takada J, Wakisaka M, Ibayashi S, Utsumi H, and Iida M. Nox4 as the major catalytic component of an endothelial NAD(P)H oxidase. Circulation 109: 227-233, 2004.

2. Ago T, Kuribayashi F, Hiroaki H, Takeya R, Ito T, Kohda $\mathrm{D}$, and Sumimoto H. Phosphorylation of $\mathrm{p} 47$ phox directs phox homology domain from SH3 domain toward phosphoinositides, leading to phagocyte NADPH oxidase activation. Proc Natl Acad Sci U S A 100: 4474-4479, 2003.

3. Ago T, Kuroda J, Pain J, Fu C, Li H, and Sadoshima J. Upregulation of Nox 4 by hypertrophic stimuli promotes apoptosis and mitochondrial dysfunction in cardiac myocytes. Circ Res 106: 1253-1264, 2010.

4. Akbar S, Bellary S, and Griffiths HR. Dietary antioxidant interventions in type 2 diabetes patients: a meta-analysis. Br J Diabetes Vasc Dis 11: 62-68, 2011.

5. Anvari E, Wikstrom $P$, Walum E, and Welsh N. The novel NADPH oxidase 4 inhibitor GLX351322 counteracts glucose intolerance in high-fat diet-treated C57BL/6 mice. Free Radic Res 49: 1308-1318, 2015.

6. Aoyama T, Paik YH, Watanabe S, Laleu B, Gaggini F, Fioraso-Cartier L, Molango S, Heitz F, Merlot C, Szyndralewiez C, Page P, and Brenner DA. Nicotinamide adenine dinucleotide phosphate oxidase in experimental liver 
fibrosis: GKT137831 as a novel potential therapeutic agent. Hepatology 56: 2316-2327, 2012.

7. Asaba K, Tojo A, Onozato ML, Goto A, Quinn MT, Fujita $\mathrm{T}$, and Wilcox CS. Effects of NADPH oxidase inhibitor in diabetic nephropathy. Kidney Int 67: 1890-1898, 2005.

8. Attisano L and Wrana JL. Signal transduction by the TGF$\beta$ superfamily. Science 296: 1646-1647, 2002.

9. Babelova A, Avaniadi D, Jung O, Fork C, Beckmann J, Kosowski J, Weissmann N, Anilkumar N, Shah AM, Schaefer L, Schroder K, and Brandes RP. Role of Nox4 in murine models of kidney disease. Free Radic Biol Med 53: 842-853, 2012.

10. Babior BM. NADPH oxidase: an update. Blood 93: 14641476, 1999.

11. Babior BM, Kipnes RS, and Curnutte JT. Biological defense mechanisms. The production by leukocytes of superoxide, a potential bactericidal agent. J Clin Invest 52: 741-744, 1973.

12. Banfi B, Malgrange B, Knisz J, Steger K, Dubois-Dauphin $\mathrm{M}$, and Krause KH. NOX3, a superoxide-generating NADPH oxidase of the inner ear. J Biol Chem 279: 4606546072, 2004.

13. Banfi B, Maturana A, Jaconi S, Arnaudeau S, Laforge T, Sinha B, Ligeti E, Demaurex N, and Krause KH. A mammalian $\mathrm{H}+$ channel generated through alternative splicing of the NADPH oxidase homolog NOH-1. Science 287: 138$142,2000$.

14. Banfi B, Tirone F, Durussel I, Knisz J, Moskwa P, Molnar GZ, Krause KH, and Cox JA. Mechanism of Ca2+ activation of the NADPH oxidase 5 (NOX5). $J$ Biol Chem 279: 18583-18591, 2004.

15. Baricos WH, Cortez SL, Deboisblanc M, and Xin S. Transforming growth factor-beta is a potent inhibitor of extracellular matrix degradation by cultured human mesangial cells. J Am Soc Nephrol 10: 790-795, 1999.

16. Barnes JL and Gorin Y. Myofibroblast differentiation during fibrosis: role of $\mathrm{NAD}(\mathrm{P}) \mathrm{H}$ oxidases. Kidney Int 79: 944-956, 2011.

17. Batandier C, Leverve X, and Fontaine E. Opening of the mitochondrial permeability transition pore induces reactive oxygen species production at the level of the respiratory chain complex I. J Biol Chem 279: 17197-17204, 2004.

18. Bedard K and Krause K-H. The NOX family of ROSgenerating NADPH oxidases: physiology and pathophysiology. Physiol Rev 87: 245-313, 2007.

19. BelAiba RS, Djordjevic T, Petry A, Diemer K, Bonello S, Banfi B, Hess J, Pogrebniak A, Bickel C, and Gorlach A. NOX5 variants are functionally active in endothelial cells. Free Radic Biol Med 42: 446-459, 2007.

20. Beyer RE. An analysis of the role of coenzyme Q in free radical generation and as an antioxidant. Biochem Cell Biol 70: 390-403, 1992.

21. Block K, Eid A, Griendling KK, Lee D-Y, Wittrant Y, and Gorin Y. Nox4 NAD(P)H oxidase mediates Src-dependent tyrosine phosphorylation of PDK-1 in response to angiotensin II: role in mesangial cell hypertrophy and fibronectin expression. J Biol Chem 283: 24061-24076, 2008.

22. Block K, Gorin Y, and Abboud HE. Subcellular localization of Nox4 and regulation in diabetes. Proc Natl Acad Sci U S A 106: 14385-14390, 2009.

23. Bokoch GM and Zhao T. Regulation of the phagocyte NADPH oxidase by Rac GTPase. Antioxid Redox Signal 8: 1533-1548, 2006.

24. Bondi CD, Manickam N, Lee DY, Block K, Gorin Y, Abboud HE, and Barnes JL. NAD(P)H oxidase mediates
TGF-beta1-induced activation of kidney myofibroblasts. $J$ Am Soc Nephrol 21: 93-102, 2010.

25. This reference has been deleted.

26. Bonventre JV and Weinberg JM. Recent advances in the pathophysiology of ischemic acute renal failure. J Am Soc Nephrol 14: 2199-2210, 2003.

27. Broekema M, Harmsen MC, van Luyn MJ, Koerts JA, Petersen AH, van Kooten TG, van Goor H, Navis G, and Popa ER. Bone marrow-derived myofibroblasts contribute to the renal interstitial myofibroblast population and produce procollagen I after ischemia/reperfusion in rats. $\mathrm{J} \mathrm{Am}$ Soc Nephrol 18: 165-175, 2007.

28. Brosius FC. Susceptible mice: identifying a diabetic nephropathy disease locus using a murine model. Kidney Int 78: 431-432, 2010.

29. Brownlee M. Biochemistry and molecular cell biology of diabetic complications. Nature 414: 813-820, 2001.

30. Brownlee $\mathrm{M}$. The pathobiology of diabetic complications: a unifying mechanism. Diabetes 54: 1615-1625, 2005.

31. This reference has been deleted.

32. Brunskill EW and Potter SS. Changes in the gene expression programs of renal mesangial cells during diabetic nephropathy. BMC Nephrol 13: 70, 2012.

33. Budanov AV. Stress-responsive sestrins link p53 with redox regulation and mammalian target of rapamycin signaling. Antioxid Redox Signal 15: 1679-1690, 2011.

34. Burns WC, Twigg SM, Forbes JM, Pete J, Tikellis C, Thallas-Bonke V, Thomas MC, Cooper ME, and Kantharidis $P$. Connective tissue growth factor plays an important role in advanced glycation end product-induced tubular epithelialto-mesenchymal transition: implications for diabetic renal disease. J Am Soc Nephrol 17: 2484-2494, 2006.

35. Chabrashvili T, Kitiyakara C, Blau J, Karber A, Aslam S, Welch WJ, and Wilcox CS. Effects of ANG II type 1 and 2 receptors on oxidative stress, renal NADPH oxidase, and SOD expression. Am J Physiol Regul Integr Comp Physiol 285: R117-R124, 2003.

36. Chabrashvili T, Tojo A, Onozato ML, Kitiyakara C, Quinn MT, Fujita T, Welch WJ, and Wilcox CS. Expression and cellular localization of classic NADPH oxidase subunits in the spontaneously hypertensive rat kidney. Hypertension 39: 269-274, 2002.

37. Chacko Balu K, Reily C, Srivastava A, Johnson Michelle S, Ye Y, Ulasova E, Agarwal A, Zinn Kurt R, Murphy Michael P, Kalyanaraman B, and Darley-Usmar V. Prevention of diabetic nephropathy in Ins2(+/-AkitaJ) mice by the mitochondriatargeted therapy MitoQ. Biochem J 432: 9-19, 2010.

38. Chalupsky K and Cai H. Endothelial dihydrofolate reductase: critical for nitric oxide bioavailability and role in angiotensin II uncoupling of endothelial nitric oxide synthase. Proc Natl Acad Sci U S A 102: 9056-9061, 2005.

39. Chang P-C, Chen T-H, Chang C-J, Hou C-C, Chan P, and Lee $\mathrm{H}-\mathrm{M}$. Advanced glycosylation end products induce inducible nitric oxide synthase (iNOS) expression via a p38 MAPKdependent pathway. Kidney Int 65: 1664-1675, 2004.

40. Chen J, Chen J-K, and Harris RC. Angiotensin II induces epithelial-to-mesenchymal transition in renal epithelial cells through reactive oxygen species/Src/caveolin-mediated activation of an epidermal growth factor receptor-extracellular signal-regulated kinase signaling pathway. Mol Cell Biol 32: 981-991, 2012.

41. This reference has been deleted.

42. Chen S, Jim B, and Ziyadeh FN. Diabetic nephropathy and transforming growth factor-beta: transforming our 
view of glomerulosclerosis and fibrosis build-up. Semin Nephrol 23: 532-543, 2003.

43. Cheng G, Cao Z, Xu X, van Meir EG, and Lambeth JD. Homologs of gp91phox: cloning and tissue expression of Nox3, Nox4, and Nox5. Gene 269: 131-140, 2001.

44. Cheng J and Grande JP. Transforming growth factor-beta signal transduction and progressive renal disease. Exp Biol Med (Maywood) 227: 943-956, 2002.

45. Chiarelli F, Cipollone F, Romano F, Tumini S, Costantini F, di Ricco L, Pomilio M, Pierdomenico SD, Marini M, Cuccurullo F, and Mezzetti A. Increased circulating nitric oxide in young patients with type 1 diabetes and persistent microalbuminuria: relation to glomerular hyperfiltration. Diabetes 49: 1258-1263, 2000.

46. Chow F, Ozols E, Nikolic-Paterson DJ, Atkins RC, and Tesch GH. Macrophages in mouse type 2 diabetic nephropathy: correlation with diabetic state and progressive renal injury. Kidney Int 65: 116-128, 2004.

47. Chow FY, Nikolic-Paterson DJ, Atkins RC, and Tesch GH. Macrophages in streptozotocin-induced diabetic nephropathy: potential role in renal fibrosis. Nephrol Dial Transplant 19: 2987-2996, 2004.

48. Clempus RE, Sorescu D, Dikalova AE, Pounkova L, Jo P, Sorescu GP, Schmidt HH, Lassegue B, and Griendling KK. Nox 4 is required for maintenance of the differentiated vascular smooth muscle cell phenotype. Arterioscler Thromb Vasc Biol 27: 42-48, 2007.

49. Colas C and Ortiz de Montellano PR. Autocatalytic radical reactions in physiological prosthetic heme modification. Chem Rev 103: 2305-2332, 2003.

50. Cooper ME. Pathogenesis, prevention, and treatment of diabetic nephropathy. Lancet 352: 213-219, 1998.

51. Cooper ME, Mundel P, and Boner G. Role of nephrin in renal disease including diabetic nephropathy. Semin $\mathrm{Ne}$ phrol 22: 393-398, 2002.

52. Cooper ME, Vranes D, Youssef S, Stacker SA, Cox AJ, Rizkalla B, Casley DJ, Bach LA, Kelly DJ, and Gilbert RE. Increased renal expression of vascular endothelial growth factor (VEGF) and its receptor VEGFR-2 in experimental diabetes. Diabetes 48: 2229-2239, 1999.

53. Coughlan MT, Thorburn DR, Penfold SA, Laskowski A, Harcourt BE, Sourris KC, Tan AL, Fukami K, ThallasBonke V, Nawroth PP, Brownlee M, Bierhaus A, Cooper $\mathrm{ME}$, and Forbes JM. RAGE-induced cytosolic ROS promote mitochondrial superoxide generation in diabetes. $J$ Am Soc Nephrol 20: 742-752, 2009.

54. This reference has been deleted.

55. Dalla Vestra M, Saller A, Mauer M, and Fioretto P. Role of mesangial expansion in the pathogenesis of diabetic nephropathy. J Nephrol 14 Suppl 4: S51-S57, 2001.

56. Das R, Xu S, Quan X, Nguyen TT, Kong ID, Chung CH, Lee EY, Cha SK, and Park KS. Upregulation of mitochondrial Nox4 mediates TGF-beta-induced apoptosis in cultured mouse podocytes. Am J Physiol Renal Physiol 306: F155-F167, 2014.

57. De Deken X, Wang D, Dumont JE, and Miot F. Characterization of ThOX proteins as components of the thyroid $\mathrm{H}(2) \mathrm{O}(2)-$ generating system. Exp Cell Res 273: 187-196, 2002.

58. De Deken X, Wang D, Many MC, Costagliola S, Libert F, Vassart G, Dumont JE, and Miot F. Cloning of two human thyroid cDNAs encoding new members of the NADPH oxidase family. J Biol Chem 275: 23227-23233, 2000.

59. de Haan JB. Nrf2 activators as attractive therapeutics for diabetic nephropathy. Diabetes 60: 2683-2684, 2011.
60. De Vriese AS, Stoenoiu MS, Elger M, Devuyst O, Vanholder R, Kriz W, and Lameire NH. Diabetes-induced microvascular dysfunction in the hydronephrotic kidney: role of nitric oxide. Kidney Int 60: 202-210, 2001.

61. Decoursey TE and Ligeti E. Regulation and termination of NADPH oxidase activity. Cell Mol Life Sci 62: 21732193, 2005.

62. Deliyanti D and Wilkinson-Berka JL. Inhibition of NOX1/ 4 with GKT137831: a potential novel treatment to attenuate neuroglial cell inflammation in the retina. $\mathrm{J} \mathrm{Neu}$ roinflammation 12: 136, 2015.

63. Dhaunsi GS, Kaur J, Alsaeid K, Turner RB, and Bitar MS. Very long chain fatty acids activate NADPH oxidase in human dermal fibroblasts. Cell Biochem Funct 23: 65-68, 2005.

64. Dikalov SI, Dikalova AE, Bikineyeva AT, Schmidt HH, Harrison DG, and Griendling KK. Distinct roles of Nox1 and Nox4 in basal and angiotensin II-stimulated superoxide and hydrogen peroxide production. Free Radic Biol Med 45: 1340-1351, 2008.

65. Ding G, Reddy K, Kapasi AA, Franki N, Gibbons N, Kasinath BS, and Singhal PC. Angiotensin II induces apoptosis in rat glomerular epithelial cells. Am J Physiol Renal Physiol 283: F173-F180, 2002.

66. Ding $\mathrm{H}$, Aljofan $\mathrm{M}$, and Triggle CR. Oxidative stress and increased eNOS and NADPH oxidase expression in mouse microvessel endothelial cells. J Cell Physiol 212: 682-689, 2007.

67. Ding Y, Chen ZJ, Liu S, Che D, Vetter M, and Chang CH. Inhibition of Nox-4 activity by plumbagin, a plant-derived bioactive naphthoquinone. J Pharm Pharmacol 57: 111116, 2005.

68. Doublier S, Salvidio G, Lupia E, Ruotsalainen V, Verzola D, Deferrari G, and Camussi G. Nephrin expression is reduced in human diabetic nephropathy: evidence for a distinct role for glycated albumin and angiotensin II. Diabetes 52: 1023-1030, 2003.

69. Dugan LL, You Y-H, Ali SS, Diamond-Stanic M, Miyamoto S, DeCleves A-E, Andreyev A, Quach T, Ly S, Shekhtman G, Nguyen W, Chepetan A, Le TP, Wang L, Xu M, Paik KP, Fogo A, Viollet B, Murphy A, Brosius F, Naviaux RK, and Sharma K. AMPK dysregulation promotes diabetes-related reduction of superoxide and mitochondrial function. J Clin Invest 123: 4888-4899, 2013.

70. This reference has been deleted.

71. Dupuy C, Ohayon R, Valent A, Noel-Hudson MS, Deme D, and Virion A. Purification of a novel flavoprotein involved in the thyroid NADPH oxidase. Cloning of the porcine and human cdnas. J Biol Chem 274: 37265-37269, 1999.

72. Durvasula RV and Shankland SJ. Activation of a local renin angiotensin system in podocytes by glucose. Am J Physiol Renal Physiol 294: F830-F839, 2008.

73. Eid AA, Ford BM, Block K, Kasinath BS, Gorin Y, Ghosh-Choudhury G, Barnes JL, and Abboud HE. AMPactivated protein kinase (AMPK) negatively regulates Nox4-dependent activation of p53 and epithelial cell apoptosis in diabetes. J Biol Chem 285: 37503-37512, 2010.

74. Eid AA, Gorin Y, Fagg BM, Maalouf R, Barnes JL, Block $\mathrm{K}$, and Abboud HE. Mechanisms of podocyte injury in diabetes: role of cytochrome P450 and NADPH oxidases. Diabetes 58: 1201-1211, 2009.

75. Eid AA, Lee DY, Roman LJ, Khazim K, and Gorin Y. Sestrin 2 and AMPK connect hyperglycemia to Nox4-dependent endothelial nitric oxide synthase uncoupling and matrix protein expression. Mol Cell Biol 33: 3439-3460, 2013. 
76. El-Demerdash E, Awad AS, Taha RM, El-Hady AM, and Sayed-Ahmed MM. Probucol attenuates oxidative stress and energy decline in isoproterenol-induced heart failure in rat. Pharmacol Res 51: 311-318, 2005.

77. El Jamali A, Valente AJ, and Clark RA. Regulation of phagocyte NADPH oxidase by hydrogen peroxide through a $\mathrm{Ca}(2+) / \mathrm{c}-\mathrm{Abl}$ signaling pathway. Free Radic Biol Med 48: 798-810, 2010.

78. El Jamali A, Valente AJ, Lechleiter JD, Gamez MJ, Pearson DW, Nauseef WM, and Clark RA. Novel redoxdependent regulation of NOX5 by the tyrosine kinase cAbl. Free Radic Biol Med 44: 868-881, 2008.

79. Elahi MM, Naseem KM, and Matata BM. Nitric oxide in blood. The nitrosative-oxidative disequilibrium hypothesis on the pathogenesis of cardiovascular disease. FEBS $J$ 274: 906-923, 2007.

80. Etoh T, Inoguchi T, Kakimoto M, Sonoda N, Kobayashi K, Kuroda J, Sumimoto H, and Nawata H. Increased expression of $\mathrm{NAD}(\mathrm{P}) \mathrm{H}$ oxidase subunits, NOX4 and p22phox, in the kidney of streptozotocin-induced diabetic rats and its reversibity by interventive insulin treatment. Diabetologia 46: 1428-1437, 2003.

81. Feraille E, Dizin E, Roth I, Derouette JP, Szanto I, Martin PY, de Seigneux S, and Hasler U. NADPH oxidase 4 deficiency reduces aquaporin-2 mRNA expression in cultured renal collecting duct principal cells via increased PDE3 and PDE4 activity. PLoS One 9: e87239, 2014.

82. Ferreira SM, Lerner SF, Brunzini R, Evelson PA, and Llesuy SF. Oxidative stress markers in aqueous humor of glaucoma patients. Am J Ophthalmol 137: 62-69, 2004.

83. Forbes JM and Cooper ME. Mechanisms of diabetic complications. Physiol Rev 93: 137-188, 2013.

84. Forbes JM, Coughlan MT, and Cooper ME. Oxidative stress as a major culprit in kidney disease in diabetes. Diabetes 57: 1446-1454, 2008.

85. Ford BM, Eid AA, Gooz M, Barnes JL, Gorin YC, and Abboud HE. ADAM17 mediates Nox4 expression and NADPH oxidase activity in the kidney cortex of OVE26 mice. Am J Physiol Renal Physiol 305: F323-332, 2013.

86. Fu Y, Zhang Y, Wang Z, Wang L, Wei X, Zhang B, Wen Z, Fang H, Pang Q, and Yi F. Regulation of NADPH oxidase activity is associated with miRNA-25-mediated NOX4 expression in experimental diabetic nephropathy. Am J Nephrol 32: 581-589, 2010.

87. Fujii M, Inoguchi T, Maeda Y, Sasaki S, Sawada F, Saito R, Kobayashi K, Sumimoto H, and Takayanagi R. Pitavastatin ameliorates albuminuria and renal mesangial expansion by downregulating NOX4 in $\mathrm{db} / \mathrm{db}$ mice. Kidney Int 72: 473-480, 2007.

88. Fulton DJ. Nox 5 and the regulation of cellular function. Antioxid Redox Signal 11: 2443-2452, 2009.

89. Gaggini F, Laleu B, Orchard M, Fioraso-Cartier L, Cagnon L, Houngninou-Molango S, Gradia A, Duboux G, Merlot C, Heitz F, Szyndralewiez C, and Page P. Design, synthesis and biological activity of original pyrazolopyrido-diazepine, -pyrazine and -oxazine dione derivatives as novel dual Nox4/Nox1 inhibitors. Bioorg Med Chem 19: 6989-6999, 2011.

90. Gao L, Huang W, and Li J. NOX1 abet mesangial fibrogenesis via iNOS induction in diabetes. Mol Cell Biochem 382: 185-191, 2013.

91. Geiszt M, Kopp JB, Varnai P, and Leto TL. Identification of renox, an NAD(P)H oxidase in kidney. Proc Natl Acad Sci U S A 97: 8010-8014, 2000.
92. Gill PS and Wilcox CS. NADPH oxidases in the kidney. Antioxid Redox Signal 8: 1597-1607, 2006.

93. Giorgi C, Agnoletto C, Baldini C, Bononi A, Bonora M, Marchi S, Missiroli S, Patergnani S, Poletti F, Rimessi A, Zavan B, and Pinton P. Redox control of protein kinase C: cell- and disease-specific aspects. Antioxid Redox Signal 13: 1051-1085, 2010.

94. Gojo A, Utsunomiya K, Taniguchi K, Yokota T, Ishizawa S, Kanazawa Y, Kurata H, and Tajima N. The Rho-kinase inhibitor, fasudil, attenuates diabetic nephropathy in streptozotocin-induced diabetic rats. Eur J Pharmacol 568: 242-247, 2007.

95. Gorin Y and Block K. Nox4 and diabetic nephropathy: with a friend like this, who needs enemies? Free Radic Biol Med 61: 130-142, 2013.

96. Gorin Y, Block K, Hernandez J, Bhandari B, Wagner B, Barnes JL, and Abboud HE. Nox4 NAD $(\mathrm{P}) \mathrm{H}$ oxidase mediates hypertrophy and fibronectin expression in the diabetic kidney. J Biol Chem 280: 39616-39626, 2005.

97. Gorin Y, Cavaglieri RC, Khazim K, Lee DY, Bruno F, Thakur S, Fanti P, Szyndralewiez C, Barnes JL, Block K, and Abboud HE. Targeting NADPH oxidase with a novel dual Nox1/Nox4 inhibitor attenuates renal pathology in type 1 diabetes. Am J Physiol Renal Physiol 308: F1276-1287, 2015.

98. This reference has been deleted.

99. Gorin Y, Ricono JM, Kim NH, Bhandari B, Choudhury GG, and Abboud HE. Nox4 mediates angiotensin IIinduced activation of Akt/protein kinase B in mesangial cells. Am J Physiol Renal Physiol 285: F219-F229, 2003.

100. Goyal P, Weissmann N, Rose F, Grimminger F, Schafers HJ, Seeger W, and Hanze J. Identification of novel Nox4 splice variants with impact on ROS levels in A549 cells. Biochem Biophys Res Commun 329: 32-39, 2005.

101. Graham S, Gorin Y, Abboud HE, Ding M, Lee DY, Shi H, Ding Y, and Ma R. Abundance of TRPC6 protein in glomerular mesangial cells is decreased by ROS and PKC in diabetes. Am J Physiol Cell Physiol 301: C304-C315, 2011.

102. Grasberger H and Refetoff S. Identification of the maturation factor for dual oxidase. Evolution of an eukaryotic operon equivalent. J Biol Chem 281: 18269-18272, 2006.

103. Gray SP, Di Marco E, Okabe J, Szyndralewiez C, Heitz F, Montezano AC, de Haan JB, Koulis C, El-Osta A, Andrews KL, Chin-Dusting JP, Touyz RM, Wingler K, Cooper ME, Schmidt HH, and Jandeleit-Dahm KA. NADPH oxidase 1 plays a key role in diabetes mellitus-accelerated atherosclerosis. Circulation 127: 1888-1902, 2013.

104. Greiber S, Munzel T, Kastner S, Muller B, Schollmeyer P, and Pavenstadt H. NAD(P)H oxidase activity in cultured human podocytes: effects of adenosine triphosphate. Kidney Int 53: 654-663, 1998.

105. Grobe AC, Wells SM, Benavidez E, Oishi P, Azakie A, Fineman JR, and Black SM. Increased oxidative stress in lambs with increased pulmonary blood flow and pulmonary hypertension: role of NADPH oxidase and endothelial NO synthase. Am J Physiol Lung Cell Mol Physiol 290: L1069-L1077, 2006.

106. Guijarro C and Egido J. Transcription factor-kappa B (NFkappa B) and renal disease. Kidney Int 59: 415-424, 2001.

107. Guzik TJ, Chen W, Gongora MC, Guzik B, Lob HE, Mangalat D, Hoch N, Dikalov S, Rudzinski P, Kapelak B, Sadowski J, and Harrison DG. Calcium dependent Nox5 NADPH oxidase contributes to vascular oxidative stress in human coronary artery disease. J Am Coll Cardiol 52: 1803-1809, 2008. 
108. Harper RW, Xu C, Soucek K, Setiadi H, and Eiserich JP. A reappraisal of the genomic organization of human Nox 1 and its splice variants. Arch Biochem Biophys 435: 323330, 2005.

109. Harrison CB, Selemidis S, Guida E, King PT, Sobey CG, and Drummond GR. NOX2beta: a novel splice variant of NOX2 that regulates NADPH oxidase activity in macrophages. PLoS One 7: e48326, 2012.

110. He T, Guan X, Wang S, Xiao T, Yang K, Xu X, Wang J, and Zhao J. Resveratrol prevents high glucose-induced epithelial-mesenchymal transition in renal tubular epithelial cells by inhibiting NADPH oxidase/ROS/ERK pathway. Mol Cell Endocrinol 402: 13-20, 2015.

111. Hellemons ME, Kerschbaum J, Bakker SJ, Neuwirt H, Mayer B, Mayer G, de Zeeuw D, Lambers Heerspink HJ, and Rudnicki M. Validity of biomarkers predicting onset or progression of nephropathy in patients with Type 2 diabetes: a systematic review. Diabet Med 29: 567-577, 2012.

112. Heumuller S, Wind S, Barbosa-Sicard E, Schmidt HH, Busse R, Schroder K, and Brandes RP. Apocynin is not an inhibitor of vascular NADPH oxidases but an antioxidant. Hypertension 51: 211-217, 2008.

113. Hilenski LL, Clempus RE, Quinn MT, Lambeth JD, and Griendling KK. Distinct subcellular localizations of Nox1 and Nox4 in vascular smooth muscle cells. Arterioscler Thromb Vasc Biol 24: 677-683, 2004.

114. Holterman CE, Thibodeau JF, Towaij C, Gutsol A, Montezano AC, Parks RJ, Cooper ME, Touyz RM, and Kennedy CR. Nephropathy and elevated BP in mice with podocyte-specific NADPH oxidase 5 expression. J Am Soc Nephrol 25: 784-797, 2014.

115. Hong NJ and Garvin JL. NADPH oxidase 4 mediates flowinduced superoxide production in thick ascending limbs. Am J Physiol Renal Physiol 303: F1151-F1156, 2012.

116. Hsieh TJ, Zhang SL, Filep JG, Tang SS, Ingelfinger JR, and Chan JS. High glucose stimulates angiotensinogen gene expression via reactive oxygen species generation in rat kidney proximal tubular cells. Endocrinology 143: 2975-2985, 2002.

117. Iglesias-de la Cruz MC, Ziyadeh FN, Isono M, Kouahou M, Han DC, Kalluri R, Mundel P, and Chen S. Effects of high glucose and TGF-beta1 on the expression of collagen IV and vascular endothelial growth factor in mouse podocytes. Kidney Int 62: 901-913, 2002.

118. Inoguchi T, Li P, Umeda F, Yu HY, Kakimoto M, Imamura M, Aoki T, Etoh T, Hashimoto T, Naruse M, Sano H, Utsumi $\mathrm{H}$, and Nawata $\mathrm{H}$. High glucose level and free fatty acid stimulate reactive oxygen species production through protein kinase $\mathrm{C}$-dependent activation of $\mathrm{NAD}(\mathrm{P}) \mathrm{H}$ oxidase in cultured vascular cells. Diabetes 49: 1939-1945, 2000.

119. Iwano $M$ and Neilson EG. Mechanisms of tubulointerstitial fibrosis. Curr Opin Nephrol Hypertens 13: 279-284, 2004.

120. Jaimes EA, Hua P, Tian R-X, and Raij L. Human glomerular endothelium: interplay among glucose, free fatty acids, angiotensin II, and oxidative stress. Am J Physiol Renal Physiol 298: F125-F132, 2010.

121. Jamaluddin M, Kim S, and Paik WK. Studies on the kinetic mechanism of S-adenosylmethionine: protein Omethyltransferase of calf thymus. Biochemistry 14: 694698, 1975.

122. Jefferson JA, Shankland SJ, and Pichler RH. Proteinuria in diabetic kidney disease: a mechanistic viewpoint. Kidney Int 74: 22-36, 2008.
123. Jerums $\mathrm{G}$, Panagiotopoulos $\mathrm{S}$, and MacIsaac R. Podocytes and diabetic nephropathy. In: The Diabetic Kidney, edited by Cortes P and Mogensen C. Totowa, NJ: Humana Press, 2006, pp. 59-77.

124. Jha JC, Gray SP, Barit D, Okabe J, El-Osta A, Namikoshi T, Thallas-Bonke V, Wingler K, Szyndralewiez C, Heitz F, Touyz RM, Cooper ME, Schmidt HH, and Jandeleit-Dahm KA. Genetic targeting or pharmacologic inhibition of NADPH oxidase nox 4 provides renoprotection in long-term diabetic nephropathy. J Am Soc Nephrol 25: 1237-1254, 2014.

125. Jha JC, Thallas-Bonke V, Banal C, Gray SP, Chow BS, Ramm G, Quaggin SE, Cooper ME, Schmidt HH, and Jandeleit-Dahm KA. Jandeleit-Dahm. Podocyte-specific Nox4 deletion affords renoprotection in a mouse model of diabetic nephropathy. Diabetologia 59: 379-389, 2016.

126. Jheng HF, Tsai PJ, Chuang YL, Shen YT, Tai TA, Chen WC, Chou CK, Ho LC, Tang MJ, Lai KT, Sung JM, and Tsai YS. Albumin stimulates renal tubular inflammation through an HSP70-TLR4 axis in mice with early diabetic nephropathy. Dis Model Mech 8: 1311-1321, 2015.

127. Jones SA, Donnell VB, Wood JD, Broughton JP, Hughes EJ, and Jones OT. Expression of phagocyte NADPH oxidase components in human endothelial cells. Am J Physiol Heart Circ Physiol 271: H1626-H1634, 1996.

128. Jones SA, Hancock JT, Jones OT, Neubauer A, and Topley N. The expression of NADPH oxidase components in human glomerular mesangial cells: detection of protein and mRNA for p47phox, p67phox, and p22phox. $J$ Am Soc Nephrol 5: 1483-1491, 1995.

129. Kaneto H, Katakami N, Kawamori D, Miyatsuka T, Sakamoto K, Matsuoka TA, Matsuhisa M, and Yamasaki Y. Involvement of oxidative stress in the pathogenesis of diabetes. Antioxid Redox Signal 9: 355-366, 2007.

130. Kang SW, Adler SG, Lapage J, and Natarajan R. p38 MAPK and MAPK kinase 3/6 mRNA and activities are increased in early diabetic glomeruli. Kidney Int 60: 543-552, 2001.

131. Kanwar YS, Wada J, Sun L, Xie P, Wallner EI, Chen S, Chugh S, and Danesh FR. Diabetic nephropathy: mechanisms of renal disease progression. Exp Biol Med (Maywood) 233: 4-11, 2008.

132. Karbach S, Jansen T, Horke S, Heeren T, Scholz A, Coldewey M, Karpi A, Hausding M, Kröller-Schön S, Oelze M, Münzel T, and Daiber A. Hyperglycemia and oxidative stress in cultured endothelial cells - a comparison of primary endothelial cells with an immortalized endothelial cell line. $J$ Diabetes Complications 26: 155-162, 2012.

133. Kaspar JW, Niture SK, and Jaiswal AK. Nrf2:INrf2 (Keap1) Signaling in oxidative stress. Free Radic Biol Med 47: 1304-1309, 2009.

134. Kensler TW, Wakabayashi N, and Biswal S. Cell survival responses to environmental stresses via the Keap1-Nrf2-ARE pathway. Annu Rev Pharmacol Toxicol 47: 89-116, 2007.

135. Khazim K, Gorin Y, Cavaglieri RC, Abboud HE, and Fanti P. The antioxidant silybin prevents high glucoseinduced oxidative stress and podocyte injury in vitro and in vivo. Am J Physiol Renal Physiol 305: F691-700, 2013.

136. Kikuchi H, Hikage M, Miyashita $\mathrm{H}$, and Fukumoto $\mathrm{M}$. NADPH oxidase subunit, gp91(phox) homologue, preferentially expressed in human colon epithelial cells. Gene 254: 237-243, 2000.

137. Kim J, Shon E, Kim CS, and Kim JS. Renal podocyte injury in a rat model of type 2 diabetes is prevented by metformin. Exp Diabetes Res 2012: 210821, 2012. 
138. Kim S-M, Kim Y-G, Jeong K-H, Lee S-H, Lee T-W, Ihm $\mathrm{C}-\mathrm{G}$, and Moon J-Y. Angiotensin II-induced mitochondrial Nox4 is a major endogenous source of oxidative stress in kidney tubular cells. PLoS One 7: e39739, 2012.

139. This reference has been deleted.

140. Kitada M, Koya D, Sugimoto T, Isono M, Araki S, Kashiwagi A, and Haneda M. Translocation of glomerular p47phox and p67phox by protein kinase C-beta activation is required for oxidative stress in diabetic nephropathy. Diabetes 52: 2603-2614, 2003.

141. Kitada M, Kume S, Imaizumi N, and Koya D. Resveratrol improves oxidative stress and protects against diabetic nephropathy through normalization of Mn-SOD dysfunction in AMPK/SIRT1-independent pathway. Diabetes 60: 634-643, 2011.

142. Klebanoff SJ. Oxygen metabolism and the toxic properties of phagocytes. Ann Intern Med 93: 480-489, 1980.

143. Klisic J, Nief V, Reyes L, and Ambuhl PM. Acute and chronic regulation of the renal $\mathrm{Na} / \mathrm{H}+$ exchanger NHE3 in rats with STZ-induced diabetes mellitus. Nephron Physiol 102: p27-p35, 2006.

144. Kolavennu V, Zeng L, Peng H, Wang Y, and Danesh FR. Targeting of RhoA/ROCK signaling ameliorates progression of diabetic nephropathy independent of glucose control. Diabetes 57: 714-723, 2008.

145. Koopman WJ, Verkaart S, Visch HJ, van der Westhuizen FH, Murphy MP, van den Heuvel LW, Smeitink JA, and Willems PH. Inhibition of complex I of the electron transport chain causes O2-. - mediated mitochondrial outgrowth. Am J Physiol Cell Physiol 288: C1440-C1450, 2005.

146. Kovac S, Angelova PR, Holmström KM, Zhang Y, Dinkova-Kostova AT, and Abramov AY. Nrf2 regulates ROS production by mitochondria and NADPH oxidase. Biochim Biophys Acta 1850: 794-801, 2015.

147. Koya D, Jirousek MR, Lin YW, Ishii H, Kuboki K, and King GL. Characterization of protein kinase $\mathrm{C}$ beta isoform activation on the gene expression of transforming growth factor-beta, extracellular matrix components, and prostanoids in the glomeruli of diabetic rats. J Clin Invest 100: 115-126, 1997.

148. Koziel R, Pircher H, Kratochwil M, Lener B, Hermann M, Dencher NA, and Jansen-Durr P. Mitochondrial respiratory chain complex I is inactivated by NADPH oxidase Nox4. Biochem J 452: 231-239, 2013.

149. Kuhad A and Chopra K. Attenuation of diabetic nephropathy by tocotrienol: involvement of NFkB signaling pathway. Life Sci 84: 296-301, 2009.

150. Kume S, Thomas MC, and Koya D. Nutrient Sensing, Autophagy, and Diabetic Nephropathy. Diabetes 61: 23-29, 2012.

151. Laleu B, Gaggini F, Orchard M, Fioraso-Cartier L, Cagnon L, Houngninou-Molango S, Gradia A, Duboux G, Merlot C, Heitz F, Szyndralewiez C, and Page P. First in class, potent, and orally bioavailable NADPH oxidase isoform 4 (Nox4) inhibitors for the treatment of idiopathic pulmonary fibrosis. J Med Chem 53: 7715-7730, 2010.

152. Lassegue $B$ and Clempus RE. Vascular NAD(P)H oxidases: specific features, expression, and regulation. Am J Physiol Regul Integr Comp Physiol 285: R277-R297, 2003.

153. Lassegue B, San Martin A, and Griendling KK. Biochemistry, physiology, and pathophysiology of NADPH oxidases in the cardiovascular system. Circ Res 110: 1364-1390, 2012.

154. Lee D-Y, Wauquier F, Eid AA, Roman LJ, GhoshChoudhury G, Khazim K, Block K, and Gorin Y. Nox4 NADPH oxidase mediates peroxynitrite-dependent un- coupling of endothelial nitric-oxide synthase and fibronectin expression in response to angiotensin II: role of mitochondrial reactive oxygen species. J Biol Chem 288: 28668-28686, 2013.

155. This reference has been deleted.

156. Lee HB, Yu M-R, Yang Y, Jiang Z, and Ha H. Reactive oxygen species-regulated signaling pathways in diabetic nephropathy. J Am Soc Nephrol 14: S241-S245, 2003.

157. This reference has been deleted.

158. Lee JH, Kim JH, Kim JS, Chang JW, Kim SB, Park JS, and Lee SK. AMP-activated protein kinase inhibits TGFbeta-, angiotensin II-, aldosterone-, high glucose-, and albumin-induced epithelial-mesenchymal transition. Am J Physiol Renal Physiol 304: F686-F697, 2013.

159. This reference has been deleted.

160. Li N, Yi FX, Spurrier JL, Bobrowitz CA, and Zou AP. Production of superoxide through NADH oxidase in thick ascending limb of Henle's loop in rat kidney. Am J Physiol Renal Physiol 282: F1111-F1119, 2002.

161. Liu BC, Song X, Lu XY, Li DT, Eaton DC, Shen BZ, Li $\mathrm{XQ}$, and Ma HP. High glucose induces podocyte apoptosis by stimulating TRPC6 via elevation of reactive oxygen species. Biochim Biophys Acta 1833: 1434-1442, 2013.

162. Lorenz G, Darisipudi MN, and Anders H-J. Canonical and non-canonical effects of the NLRP3 inflammasome in kidney inflammation and fibrosis. Nephrol Dial Transplant 29: 41-48, 2014.

163. Lyle AN, Deshpande NN, Taniyama Y, Seidel-Rogol B, Pounkova L, Du P, Papaharalambus C, Lassegue B, and Griendling KK. Poldip2, a novel regulator of Nox4 and cytoskeletal integrity in vascular smooth muscle cells. Circ Res 105: 249-259, 2009.

164. Mahimainathan L, Das F, Venkatesan B, and Choudhury GG. Mesangial cell hypertrophy by high glucose is mediated by downregulation of the tumor suppressor PTEN. Diabetes 55: 2115-2125, 2006.

165. Manickam N, Patel M, Griendling KK, Gorin Y, and Barnes JL. RhoA/Rho kinase mediates TGF-beta1induced kidney myofibroblast activation through Poldip2/ Nox4-derived reactive oxygen species. Am J Physiol Renal Physiol 307: F159-F171, 2014.

166. Mariappan MM, Feliers D, Mummidi S, Choudhury GG, and Kasinath BS. High glucose, high insulin, and their combination rapidly induce laminin-betal synthesis by regulation of mRNA translation in renal epithelial cells. Diabetes 56: 476-485, 2007.

167. Martyn KD, Frederick LM, von Loehneysen K, Dinauer $\mathrm{MC}$, and Knaus UG. Functional analysis of Nox4 reveals unique characteristics compared to other NADPH oxidases. Cell Signal 18: 69-82, 2006.

168. Mason RM and Wahab NA. Extracellular matrix metabolism in diabetic nephropathy. J Am Soc Nephrol 14: 1358-1373, 2003.

169. Massagué $\mathrm{J}$ and Gomis RR. The logic of TGF $\beta$ signaling. FEBS Lett 580: 2811-2820, 2006.

170. Massey KJ, Hong NJ, and Garvin JL. Angiotensin II stimulates superoxide production in the thick ascending limb by activating NOX4. Am J Physiol Cell Physiol 303: C781-C789, 2012.

171. Matsuno K, Yamada H, Iwata K, Jin D, Katsuyama M, Matsuki M, Takai S, Yamanishi K, Miyazaki M, Matsubara $\mathrm{H}$, and Yabe-Nishimura C. Nox1 is involved in angiotensin II-mediated hypertension: a study in Nox1-deficient mice. Circulation 112: 2677-2685, 2005. 
172. Mauer SM, Steffes MW, Ellis EN, Sutherland DE, Brown DM, and Goetz FC. Structural-functional relationships in diabetic nephropathy. J Clin Invest 74: 1143-1155, 1984.

173. McGowan TA, Zhu Y, and Sharma K. Transforming growth factor-beta: a clinical target for the treatment of diabetic nephropathy. Curr Diab Rep 4: 447-454, 2004.

174. Mehrabian M, Sparkes RS, Mohandas T, Fogelman AM, and Lusis AJ. Localization of monocyte chemotactic protein-1 gene (SCYA2) to human chromosome 17q11.2q21.1. Genomics 9: 200-203, 1991.

175. Michaud JL, Chaisson KM, Parks RJ, and Kennedy CR. FSGS-associated alpha-actinin-4 (K256E) impairs cytoskeletal dynamics in podocytes. Kidney Int 70: 1054-1061, 2006.

176. Mifsud SA, Allen TJ, Bertram JF, Hulthen UL, Kelly DJ, Cooper ME, Wilkinson-Berka JL, and Gilbert RE. Podocyte foot process broadening in experimental diabetic nephropathy: amelioration with renin-angiotensin blockade. Diabetologia 44: 878-882, 2001.

177. Modlinger P, Chabrashvili T, Gill PS, Mendonca M, Harrison DG, Griendling KK, Li M, Raggio J, Wellstein A, Chen Y, Welch WJ, and Wilcox CS. RNA silencing in vivo reveals role of $\mathrm{p} 22 \mathrm{phox}$ in rat angiotensin slow pressor response. Hypertension 47: 238-244, 2006.

178. Molitch ME, DeFronzo RA, Franz MJ, Keane WF, Mogensen CE, Parving HH, and Steffes MW. Nephropathy in diabetes. Diabetes Care 27 Suppl 1: S79-S83, 2004.

179. Montero A, Munger KA, Khan RZ, Valdivielso JM, Morrow JD, Guasch A, Ziyadeh FN, and Badr KF. F(2)isoprostanes mediate high glucose-induced TGF-beta synthesis and glomerular proteinuria in experimental type I diabetes. Kidney Int 58: 1963-1972, 2000.

180. Montezano AC, Burger D, Paravicini TM, Chignalia AZ, Yusuf H, Almasri M, He Y, Callera GE, He G, Krause K-H, Lambeth D, Quinn MT, and Touyz RM. Nicotinamide adenine dinucleotide phosphate reduced oxidase 5 (Nox5) regulation by angiotensin II and endothelin-1 is mediated via calcium/calmodulin-dependent, Rac-1-independent pathways in human endothelial cells. Circ Res 106: 1363-1373, 2010.

181. This reference has been deleted.

182. Morgan MJ and Liu ZG. Crosstalk of reactive oxygen species and NF-kappaB signaling. Cell Res 21: 103-115, 2011.

183. Nagase M, Yoshida S, Shibata S, Nagase T, Gotoda T, Ando K, and Fujita T. Enhanced aldosterone signaling in the early nephropathy of rats with metabolic syndrome: possible contribution of fat-derived factors. $J$ Am Soc Nephrol 17: 3438-3446, 2006.

184. Nakagawa T, Sato W, Sautin YY, Glushakova O, Croker B, Atkinson MA, Tisher CC, and Johnson RJ. Uncoupling of vascular endothelial growth factor with nitric oxide as a mechanism for diabetic vasculopathy. J Am Soc Nephrol 17: 736-745, 2006.

185. Nakamura N, Matsui T, Ishibashi Y, and Yamagishi S. Insulin stimulates SGLT2-mediated tubular glucose absorption via oxidative stress generation. Diabetol Metab Syndr 7: 48, 2015.

186. Navarro JF, Milena FJ, Mora C, Leon C, and Garcia J. Renal pro-inflammatory cytokine gene expression in diabetic nephropathy: effect of angiotensin-converting enzyme inhibition and pentoxifylline administration. Am J Nephrol 26: 562-570, 2006.

187. New DD, Block K, Bhandhari B, Gorin Y, and Abboud HE. IGF-I increases the expression of fibronectin by Nox4- dependent Akt phosphorylation in renal tubular epithelial cells. Am J Physiol Cell Physiol 302: C122-C130, 2012.

188. Nishikawa T, Edelstein D, Du XL, Yamagishi S, Matsumura T, Kaneda Y, Yorek MA, Beebe D, Oates PJ, Hammes H-P, Giardino I, and Brownlee M. Normalizing mitochondrial superoxide production blocks three pathways of hyperglycaemic damage. Nature 404: 787-790, 2000.

189. Nishiyama A, Yoshizumi M, Hitomi H, Kagami S, Kondo S, Miyatake A, Fukunaga M, Tamaki T, Kiyomoto H, Kohno M, Shokoji T, Kimura S, and Abe Y. The SOD mimetic tempol ameliorates glomerular injury and reduces mitogen-activated protein kinase activity in Dahl saltsensitive rats. J Am Soc Nephrol 15: 306-315, 2004.

190. Nistala R, Whaley-Connell A, and Sowers JR. Redox control of renal function and hypertension. Antioxid Redox Signal 10: 2047-2089, 2008.

191. Niu J and Kolattukudy PE. Role of MCP-1 in cardiovascular disease: molecular mechanisms and clinical implications. Clin Sci (Lond) 117: 95-109, 2009.

192. Nlandu Khodo S, Dizin E, Sossauer G, Szanto I, Martin PY, Feraille E, Krause KH, and de Seigneux S. NADPHoxidase 4 protects against kidney fibrosis during chronic renal injury. J Am Soc Nephrol 23: 1967-1976, 2012.

193. Oak JH and Cai H. Attenuation of angiotensin II signaling recouples eNOS and inhibits nonendothelial NOX activity in diabetic mice. Diabetes 56: 118-126, 2007.

194. Ohshiro Y, Ma RC, Yasuda Y, Hiraoka-Yamamoto J, Clermont AC, Isshiki K, Yagi K, Arikawa E, Kern TS, and King GL. Reduction of diabetes-induced oxidative stress, fibrotic cytokine expression, and renal dysfunction in protein kinase Cbeta-null mice. Diabetes 55: 3112-3120, 2006.

195. Olukman M, Orhan CE, Celenk FG, and Ulker S. Apocynin restores endothelial dysfunction in streptozotocin diabetic rats through regulation of nitric oxide synthase and NADPH oxidase expressions. J Diabetes Complications 24: 415-423, 2010.

196. Onozato ML, Tojo A, Goto A, Fujita T, and Wilcox CS. Oxidative stress and nitric oxide synthase in rat diabetic nephropathy: effects of ACEI and ARB. Kidney Int 61: 186194, 2002.

197. Ozbek E. Induction of oxidative stress in kidney. Int $J$ Nephrol 2012: 9, 2012.

198. Pacher P, Obrosova IG, Mabley JG, and Szabo C. Role of nitrosative stress and peroxynitrite in the pathogenesis of diabetic complications. Emerging new therapeutical strategies. Curr Med Chem 12: 267-275, 2005.

199. Paffenholz R, Bergstrom RA, Pasutto F, Wabnitz P, Munroe RJ, Jagla W, Heinzmann U, Marquardt A, Bareiss A, Laufs J, Russ A, Stumm G, Schimenti JC, and Bergstrom DE. Vestibular defects in head-tilt mice result from mutations in Nox3, encoding an NADPH oxidase. Genes Dev 18: 486-491, 2004.

200. Pagtalunan ME, Miller PL, Jumping-Eagle S, Nelson RG, Myers BD, Rennke HG, Coplon NS, Sun L, and Meyer TW. Podocyte loss and progressive glomerular injury in type II diabetes. J Clin Invest 99: 342-348, 1997.

201. Palicz A, Foubert TR, Jesaitis AJ, Marodi L, and McPhail LC. Phosphatidic acid and diacylglycerol directly activate NADPH oxidase by interacting with enzyme components. J Biol Chem 276: 3090-3097, 2001.

201a. Pan Q, Yang X-H, Cheng Y-X. Angiotensin II stimulates MCP-1 production in rat glomerular endothelial cells via NAD(P)H oxidase-dependent nuclear factor-kappa B signaling. Braz J Med Biol Res 42: 531-536, 2009. 
202. Pandey D, Patel A, Patel V, Chen F, Qian J, Wang Y, Barman SA, Venema RC, Stepp DW, Rudic RD, and Fulton DJ. Expression and functional significance of NADPH oxidase 5 (Nox5) and its splice variants in human blood vessels. Am J Physiol Heart Circ Physiol 302: H1919-H1928, 2012.

203. Papadimitriou A, Peixoto EB, Silva KC, Lopes de Faria JM, and Lopes de Faria JB. Increase in AMPK brought about by cocoa is renoprotective in experimental diabetes mellitus by reducing NOX4/TGFbeta-1 signaling. $J$ Nutr Biochem 25: 773-784, 2014.

204. Park HS, Chun JN, Jung HY, Choi C, and Bae YS. Role of NADPH oxidase 4 in lipopolysaccharide-induced proinflammatory responses by human aortic endothelial cells. Cardiovasc Res 72: 447-455, 2006.

205. Pecoits-Filho R, Lindholm B, Axelsson J, and Stenvinkel P. Update on interleukin-6 and its role in chronic renal failure. Nephrol Dial Transplant 18: 1042-1045, 2003.

206. Pedruzzi E, Guichard C, Ollivier V, Driss F, Fay M, Prunet C, Marie JC, Pouzet C, Samadi M, Elbim C, O'Dowd Y, Bens M, Vandewalle A, Gougerot-Pocidalo MA, Lizard G, and Ogier-Denis E. NAD $(\mathrm{P}) \mathrm{H}$ oxidase Nox-4 mediates 7-ketocholesterol-induced endoplasmic reticulum stress and apoptosis in human aortic smooth muscle cells. Mol Cell Biol 24: 10703-10717, 2004.

207. Peng ZZ, Hu GY, Shen H, Wang L, Ning WB, Xie YY, Wang NS, Li BX, Tang YT, and Tao LJ. Fluorofenidone attenuates collagen I and transforming growth factor-beta1 expression through a nicotinamide adenine dinucleotide phosphate oxidase-dependent way in NRK-52E cells. Nephrology (Carlton) 14: 565-572, 2009.

208. Pergola PE, Krauth M, Huff JW, Ferguson DA, Ruiz S, Meyer CJ, and Warnock DG. Effect of bardoxolone methyl on kidney function in patients with T2D and Stage 3b-4 CKD. Am J Nephrol 33: 469-476, 2011.

209. Pergola PE, Raskin P, Toto RD, Meyer CJ, Huff JW, Grossman EB, Krauth M, Ruiz S, Audhya P, Christ-Schmidt H, Wittes J, Warnock DG, and Beam Study Investigators. Bardoxolone methyl and kidney function in CKD with type 2 diabetes. N Engl J Med 365: 327-336, 2011.

210. Persson P, Hansell P, and Palm F. NADPH oxidase inhibition reduces tubular sodium transport and improves kidney oxygenation in diabetes. Am J Physiol Regul Integr Comp Physiol 302: R1443-R1449, 2012.

211. Pieczenik SR and Neustadt J. Mitochondrial dysfunction and molecular pathways of disease. Exp Mol Pathol 83: 84-92, 2007.

212. Piwkowska A, Rogacka D, Audzeyenka I, Jankowski M, and Angielski S. High glucose concentration affects the oxidant-antioxidant balance in cultured mouse podocytes. J Cell Biochem 112: 1661-1672, 2011.

213. Pleskova M, Beck KF, Behrens MH, Huwiler A, Fichtlscherer B, Wingerter $\mathrm{O}$, Brandes RP, Mulsch A, and Pfeilschifter J. Nitric oxide down-regulates the expression of the catalytic NADPH oxidase subunit Nox1 in rat renal mesangial cells. FASEB J 20: 139-141, 2006.

214. Qi W, Niu J, Qin Q, Qiao Z, and Gu Y. Glycated albumin triggers fibrosis and apoptosis via an NADPH oxidase/Nox4MAPK pathway-dependent mechanism in renal proximal tubular cells. Mol Cell Endocrinol 405: 74-83, 2015.

215. Quack I, Woznowski M, Potthoff SA, Palmer R, Konigshausen E, Sivritas S, Schiffer M, Stegbauer J, Vonend O, Rump LC, and Sellin L. PKC alpha mediates beta-arrestin2dependent nephrin endocytosis in hyperglycemia. $J$ Biol Chem 286: 12959-12970, 2011.
216. Quaggin SE and Kreidberg JA. Development of the renal glomerulus: good neighbors and good fences. Development 135: 609-620, 2008.

217. Rhyu DY, Yang Y, Ha H, Lee GT, Song JS, Uh ST, and Lee HB. Role of reactive oxygen species in TGF- $\beta 1$ induced mitogen-activated protein kinase activation and epithelial-mesenchymal transition in renal tubular epithelial cells. J Am Soc Nephrol 16: 667-675, 2005.

218. Riser BL, Denichilo M, Cortes P, Baker C, Grondin JM, Yee J, and Narins RG. Regulation of connective tissue growth factor activity in cultured rat mesangial cells and its expression in experimental diabetic glomerulosclerosis. J Am Soc Nephrol 11: 25-38, 2000.

219. Rosca MG, Mustata TG, Kinter MT, Ozdemir AM, Kern TS, Szweda LI, Brownlee M, Monnier VM, and Weiss MF. Glycation of mitochondrial proteins from diabetic rat kidney is associated with excess superoxide formation. Am J Physiol Renal Physiol 289: F420-F430, 2005.

220. Rosen $\mathrm{P}$ and Wiernsperger NF. Metformin delays the manifestation of diabetes and vascular dysfunction in Goto-Kakizaki rats by reduction of mitochondrial oxidative stress. Diabetes Metab Res Rev 22: 323-330, 2006.

221. Rossi F and Zatti M. Biochemical aspects of phagocytosis in polymorphonuclear leucocytes. NADH and NADPH oxidation by the granules of resting and phagocytizing cells. Experientia 20: 21-23, 1964.

222. Royer-Pokora B, Kunkel LM, Monaco AP, Goff SC, Newburger PE, Baehner RL, Cole FS, Curnutte JT, and Orkin SH. Cloning the gene for an inherited human disorder-chronic granulomatous disease - on the basis of its chromosomal location. Nature 322: 32-38, 1986.

223. Russo LM, del Re E, Brown D, and Lin HY. Evidence for a role of transforming growth factor (TGF)-beta1 in the induction of postglomerular albuminuria in diabetic nephropathy: amelioration by soluble TGF-beta type II receptor. Diabetes 56: 380-388, 2007.

224. Satchell SC and Tooke JE. What is the mechanism of microalbuminuria in diabetes: a role for the glomerular endothelium? Diabetologia 51: 714-725, 2008.

225. Schiffer M, Bitzer M, Roberts IS, Kopp JB, ten Dijke P, Mundel P, and Bottinger EP. Apoptosis in podocytes induced by TGF-beta and Smad7. J Clin Invest 108: 807816, 2001.

226. Schluter T, Steinbach AC, Steffen A, Rettig R, and Grisk O. Apocynin-induced vasodilation involves Rho kinase inhibition but not NADPH oxidase inhibition. Cardiovasc Res 80: 271-279, 2008.

227. Schulz E, Jansen T, Wenzel P, Daiber A, and Munzel T. Nitric oxide, tetrahydrobiopterin, oxidative stress, and endothelial dysfunction in hypertension. Antioxid Redox Signal 10: 1115-1126, 2008.

228. Scotland RS, Chauhan S, Vallance PJ, and Ahluwalia A. An endothelium-derived hyperpolarizing factor-like factor moderates myogenic constriction of mesenteric resistance arteries in the absence of endothelial nitric oxide synthasederived nitric oxide. Hypertension 38: 833-839, 2001.

229. Sedeek M, Callera G, Montezano A, Gutsol A, Heitz F, Szyndralewiez C, Page P, Kennedy CR, Burns KD, Touyz RM, and Hebert RL. Critical role of Nox4-based NADPH oxidase in glucose-induced oxidative stress in the kidney: implications in type 2 diabetic nephropathy. Am J Physiol Renal Physiol 299: F1348-F1358, 2010.

230. Sedeek M, Gutsol A, Montezano AC, Burger D, Nguyen Dinh Cat A, Kennedy CR, Burns KD, Cooper ME, 
Jandeleit-Dahm K, Page P, Szyndralewiez C, Heitz F, Hebert RL, and Touyz RM. Renoprotective effects of a novel Nox $1 / 4$ inhibitor in a mouse model of Type 2 diabetes. Clin Sci (Lond) 124: 191-202, 2013.

231. Shah A, Xia L, Goldberg H, Lee KW, Quaggin SE, and Fantus IG. Thioredoxin-interacting protein mediates high glucose-induced reactive oxygen species generation by mitochondria and the NADPH oxidase, Nox4, in mesangial cells. J Biol Chem 288: 6835-6848, 2013.

232. Shahzad K, Bock F, Dong W, Wang H, Kopf S, Kohli S, Al-Dabet MdM, Ranjan S, Wolter J, Wacker C, Biemann $\mathrm{R}$, Stoyanov S, Reymann K, Soderkvist P, Gros O, Schwenger V, Pahernik S, Nawroth PP, Grone H-J, Madhusudhan T, and Isermann B. Nlrp3-inflammasome activation in non-myeloid-derived cells aggravates diabetic nephropathy. Kidney Int 87: 74-84, 2015.

233. Sharma K and Ziyadeh FN. Renal hypertrophy is associated with upregulation of TGF-beta 1 gene expression in diabetic BB rat and NOD mouse. Am J Physiol 267: F1094-F1101, 1994.

234. Sheehan AL, Carrell S, Johnson B, Stanic B, Banfi B, and Miller FJ, Jr. Role for Nox1 NADPH oxidase in atherosclerosis. Atherosclerosis 216: 321-326, 2011.

235. Shi XY, Hou FF, Niu HX, Wang GB, Xie D, Guo ZJ, Zhou ZM, Yang F, Tian JW, and Zhang X. Advanced oxidation protein products promote inflammation in diabetic kidney through activation of renal nicotinamide adenine dinucleotide phosphate oxidase. Endocrinology 149: 1829-1839, 2008.

236. Shiose A, Kuroda J, Tsuruya K, Hirai M, Hirakata H, Naito S, Hattori M, Sakaki Y, and Sumimoto H. A novel superoxide-producing NAD(P)H oxidase in kidney. $J$ Biol Chem 276: 1417-1423, 2001.

237. Soberman RJ. The expanding network of redox signaling: new observations, complexities, and perspectives. J Clin Invest 111: 571-574, 2003.

238. Soro-Paavonen A, Watson AM, Li J, Paavonen K, Koitka A, Calkin AC, Barit D, Coughlan MT, Drew BG, Lancaster GI, Thomas M, Forbes JM, Nawroth PP, Bierhaus A, Cooper ME, and Jandeleit-Dahm KA. Receptor for advanced glycation end products (RAGE) deficiency attenuates the development of atherosclerosis in diabetes. Diabetes 57: 2461-2469, 2008.

239. Stockand JD and Sansom SC. Glomerular mesangial cells: electrophysiology and regulation of contraction. Physiol Rev 78: 723-744, 1998.

240. Strutz F and Zeisberg M. Renal fibroblasts and myofibroblasts in chronic kidney disease. J Am Soc Nephrol 17: 2992-2998, 2006.

241. Suh YA, Arnold RS, Lassegue B, Shi J, Xu X, Sorescu D, Chung AB, Griendling KK, and Lambeth JD. Cell transformation by the superoxide-generating oxidase Mox1. Nature 401: 79-82, 1999.

242. Sumimoto H, Miyano K, and Takeya R. Molecular composition and regulation of the Nox family NAD $(\mathrm{P}) \mathrm{H}$ oxidases. Biochem Biophys Res Commun 338: 677-686, 2005.

243. Sun P, Yue P, and Wang WH. Angiotensin II stimulates epithelial sodium channels in the cortical collecting duct of the rat kidney. Am J Physiol Renal Physiol 302: F679-F687, 2012.

244. Sung SH, Ziyadeh FN, Wang A, Pyagay PE, Kanwar YS, and Chen S. Blockade of vascular endothelial growth factor signaling ameliorates diabetic albuminuria in mice. J Am Soc Nephrol 17: 3093-3104, 2006.
245. Susztak K, Raff AC, Schiffer M, and Bottinger EP. Glucose-induced reactive oxygen species cause apoptosis of podocytes and podocyte depletion at the onset of diabetic nephropathy. Diabetes 55: 225-233, 2006.

246. This reference has been deleted.

247. Takac I, Schroder K, Zhang L, Lardy B, Anilkumar N, Lambeth JD, Shah AM, Morel F, and Brandes RP. The Eloop is involved in hydrogen peroxide formation by the NADPH oxidase Nox4. J Biol Chem 286: 13304-13313, 2011.

248. Tan ALY, Sourris KC, Harcourt BE, Thallas-Bonke V, Penfold S, Andrikopoulos S, Thomas MC, Brien RC, Bierhaus A, Cooper ME, Forbes JM, and Coughlan MT. Disparate effects on renal and oxidative parameters following RAGE deletion, AGE accumulation inhibition, or dietary AGE control in experimental diabetic nephropathy. Am J Physiol Renal Physiol 298: F763-F770, 2010.

249. Teahan C, Rowe P, Parker P, Totty N, and Segal AW. The Xlinked chronic granulomatous disease gene codes for the beta-chain of cytochrome b-245. Nature 327: 720-721, 1987.

250. Tesch GH. MCP-1/CCL2: a new diagnostic marker and therapeutic target for progressive renal injury in diabetic nephropathy. Am J Physiol Renal Physiol 294: F697-F701, 2008.

251. Thallas-Bonke V, Jha JC, Gray SP, Barit D, Haller H, Schmidt HH, Coughlan MT, Cooper ME, Forbes JM, and Jandeleit-Dahm KA. Nox-4 deletion reduces oxidative stress and injury by PKC-alpha-associated mechanisms in diabetic nephropathy. Physiol Rep 2: pii: e12192, 2014.

252. Thallas-Bonke V, Thorpe SR, Coughlan MT, Fukami K, Yap FY, Sourris KC, Penfold SA, Bach LA, Cooper ME, and Forbes JM. Inhibition of NADPH oxidase prevents advanced glycation end product-mediated damage in diabetic nephropathy through a protein kinase C-alphadependent pathway. Diabetes 57: 460-469, 2008.

253. Thannickal VJ and Fanburg BL. Reactive oxygen species in cell signaling. Am J Physiol Lung Cell Mol Physiol 279: L1005-L1028, 2000.

254. Tojo A, Asaba K, and Onozato ML. Suppressing renal NADPH oxidase to treat diabetic nephropathy. Expert Opin Ther Targets 11: 1011-1018, 2007.

255. Tojo A, Onozato ML, Kobayashi N, Goto A, Matsuoka H, and Fujita T. Antioxidative effect of p38 mitogenactivated protein kinase inhibitor in the kidney of hypertensive rat. J Hypertens 23: 165-174, 2005.

256. Toto RD, Tian M, Fakouhi K, Champion A, and Bacher P. Effects of calcium channel blockers on proteinuria in patients with diabetic nephropathy. J Clin Hypertens (Greenwich) 10: 761-769, 2008.

257. Tsilibary EC. Microvascular basement membranes in diabetes mellitus. J Pathol 200: 537-546, 2003.

258. Vallet P, Charnay Y, Steger K, Ogier-Denis E, Kovari E, Herrmann F, Michel JP, and Szanto I. Neuronal expression of the NADPH oxidase NOX4, and its regulation in mouse experimental brain ischemia. Neuroscience 132: 233-238, 2005.

259. Vallon V, Platt KA, Cunard R, Schroth J, Whaley J, Thomson SC, Koepsell H, and Rieg T. SGLT2 mediates glucose reabsorption in the early proximal tubule. $J \mathrm{Am}$ Soc Nephrol 22: 104-112, 2011.

260. Wada T, Sakai N, Matsushima K, and Kaneko S. Fibrocytes: a new insight into kidney fibrosis. Kidney Int 72: 269-273, 2007. 
261. Wahab NA, Schaefer L, Weston BS, Yiannikouris O, Wright A, Babelova A, Schaefer R, and Mason RM. Glomerular expression of thrombospondin-1, transforming growth factor beta and connective tissue growth factor at different stages of diabetic nephropathy and their interdependent roles in mesangial response to diabetic stimuli. Diabetologia 48: 2650-2660, 2005.

262. Wang D, De Deken X, Milenkovic M, Song Y, Pirson I, Dumont JE, and Miot F. Identification of a novel partner of duox: EFP1, a thioredoxin-related protein. J Biol Chem 280: 3096-3103, 2005.

263. Wang H, Chen X, Su Y, Paueksakon P, Hu W, Zhang MZ, Harris RC, Blackwell TS, Zent R, and Pozzi A. p47(phox) contributes to albuminuria and kidney fibrosis in mice. Kidney Int 87: 948-962, 2015.

264. Wang HJ, Huang YL, Shih YY, Wu HY, Peng CT, and Lo WY. MicroRNA-146a decreases high glucose/thrombininduced endothelial inflammation by inhibiting NAPDH oxidase 4 expression. Mediators Inflamm 2014: 379537, 2014.

265. Wang S, Aurora AB, Johnson BA, Qi X, McAnally J, Hill JA, Richardson JA, Bassel-Duby R, and Olson EN. An endothelial-specific microRNA governs vascular integrity and angiogenesis. Dev Cell 15: 261-271, 2008.

266. Wei XF, Zhou QG, Hou FF, Liu BY, and Liang M. Advanced oxidation protein products induce mesangial cell perturbation through PKC-dependent activation of NADPH oxidase. Am J Physiol Renal Physiol 296: F427F437, 2009.

267. Weston BS, Wahab NA, and Mason RM. CTGF mediates TGF-beta-induced fibronectin matrix deposition by upregulating active alpha5beta1 integrin in human mesangial cells. J Am Soc Nephrol 14: 601-610, 2003.

268. Whaley-Connell A, Habibi J, Nistala R, Cooper SA, Karuparthi PR, Hayden MR, Rehmer N, DeMarco VG, Andresen BT, Wei Y, Ferrario C, and Sowers JR. Attenuation of NADPH oxidase activation and glomerular filtration barrier remodeling with statin treatment. Hypertension 51: 474-480, 2008.

269. Wingler K, Wunsch S, Kreutz R, Rothermund L, Paul M, and Schmidt HH. Upregulation of the vascular NAD(P)Hoxidase isoforms Nox 1 and Nox 4 by the renin-angiotensin system in vitro and in vivo. Free Radic Biol Med 31: 1456-1464, 2001.

270. Winiarska K, Jarzyna R, Dzik JM, Jagielski AK, Grabowski M, Nowosielska A, Focht D, and Sierakowski B. ERK1/2 pathway is involved in renal gluconeogenesis inhibition under conditions of lowered NADPH oxidase activity. Free Radic Biol Med 81: 13-21, 2015.

271. Wolf G, Chen S, and Ziyadeh FN. From the periphery of the glomerular capillary wall toward the center of disease: podocyte injury comes of age in diabetic nephropathy. Diabetes 54: 1626-1634, 2005.

272. Wolf G, Mueller E, Stahl RA, and Ziyadeh FN. Angiotensin II-induced hypertrophy of cultured murine proximal tubular cells is mediated by endogenous transforming growth factor-beta. J Clin Invest 92: 1366-1372, 1993.

273. Wu Y, Wu G, Qi X, Lin H, Qian H, Shen J, and Lin S. Protein kinase C beta inhibitor LY333531 attenuates intercellular adhesion molecule-1 and monocyte chemotactic protein-1 expression in the kidney in diabetic rats. $J$ Pharmacol Sci 101: 335-343, 2006.

274. Xia L, Wang H, Goldberg HJ, Munk S, Fantus IG, and Whiteside CI. Mesangial cell NADPH oxidase upregula- tion in high glucose is protein kinase $\mathrm{C}$ dependent and required for collagen IV expression. Am J Physiol Renal Physiol 290: F345-F356, 2006.

275. Xiao H, Li Y, Qi J, Wang H, and Liu K. Peroxynitrite plays a key role in glomerular lesions in diabetic rats. $J$ Nephrol 22: 800-808, 2009.

276. Xu Y, Ruan S, Xie H, and Lin J. Role of LOX-1 in Ang II-induced oxidative functional damage in renal tubular epithelial cells. Int J Mol Med 26: 679-690, 2010.

277. Yang S, Zhang Y, Ries W, and Key L. Expression of Nox4 in osteoclasts. J Cell Biochem 92: 238-248, 2004.

278. Yano M, Hasegawa G, Ishii M, Yamasaki M, Fukui M, Nakamura N, and Yoshikawa T. Short-term exposure of high glucose concentration induces generation of reactive oxygen species in endothelial cells: implication for the oxidative stress associated with postprandial hyperglycemia. Redox Report 9: 111-116, 2004.

279. Yogi A, Mercure C, Touyz J, Callera GE, Montezano AC, Aranha AB, Tostes RC, Reudelhuber T, and Touyz RM. Renal redox-sensitive signaling, but not blood pressure, is attenuated by Nox1 knockout in angiotensin II-dependent chronic hypertension. Hypertension 51: 500-506, 2008.

280. Yong R, Chen XM, Shen S, Vijayaraj S, Ma Q, Pollock $\mathrm{CA}$, and Saad S. Plumbagin ameliorates diabetic nephropathy via interruption of pathways that include NOX4 signalling. PLoS One 8: e73428, 2013.

281. You YH, Okada S, Ly S, Jandeleit-Dahm K, Barit D, Namikoshi T, and Sharma K. Role of Nox 2 in diabetic kidney disease. Am J Physiol Renal Physiol 304: F840-F848, 2013.

282. You YH, Quach T, Saito R, Pham J, and Sharma K. Metabolomics reveals a key role for fumarate in mediating the effects of NADPH oxidase 4 in diabetic kidney disease. J Am Soc Nephrol 27: 466-481, 2016.

283. Youn JY, Gao L, and Cai H. The p47phox- and NADPH oxidase organiser 1 (NOXO1)-dependent activation of NADPH oxidase 1 (NOX1) mediates endothelial nitric oxide synthase (eNOS) uncoupling and endothelial dysfunction in a streptozotocin-induced murine model of diabetes. Diabetologia 55: 2069-2079, 2012.

284. Yu P, Han W, Villar VA, Yang Y, Lu Q, Lee H, Li F, Quinn MT, Gildea JJ, Felder RA, and Jose PA. Unique role of NADPH oxidase 5 in oxidative stress in human renal proximal tubule cells. Redox Biol 2: 570-579, 2014.

285. Yue J and Mulder KM. Requirement of Ras/MAPK pathway activation by transforming growth factor $\beta$ for transforming growth factor $\beta 1$ production in a Smad-dependent pathway. $J$ Biol Chem 275: 30765-30773, 2000.

286. Zhang J, Chandrashekar K, Lu Y, Duan Y, Qu P, Wei J, Juncos LA, and Liu R. Enhanced expression and activity of Nox 2 and Nox 4 in the macula densa in ANG II-induced hypertensive mice. Am J Physiol Renal Physiol 306: F344F350, 2014.

287. Zhang M, Brewer AC, Schroder K, Santos CX, Grieve DJ, Wang M, Anilkumar N, Yu B, Dong X, Walker SJ, Brandes RP, and Shah AM. NADPH oxidase-4 mediates protection against chronic load-induced stress in mouse hearts by enhancing angiogenesis. Proc Natl Acad Sci U S A 107: 18121-18126, 2010.

288. Zhang R, Harding P, Garvin JL, Juncos R, Peterson E, Juncos $\mathrm{LA}$, and Liu R. Isoforms and functions of $\mathrm{NAD}(\mathrm{P}) \mathrm{H}$ oxidase at the macula densa. Hypertension 53: 556-563, 2009.

289. Zhao QD, Viswanadhapalli S, Williams P, Shi Q, Tan C, Yi $\mathrm{X}$, Bhandari B, and Abboud HE. NADPH oxidase 4 induces cardiac fibrosis and hypertrophy through activating Akt/ 
mTOR and NFkappaB signaling pathways. Circulation 131: 643-655, 2015.

290. Zheng H, Whitman SA, Wu W, Wondrak GT, Wong PK, Fang D, and Zhang DD. Therapeutic potential of Nrf2 activators in streptozotocin-induced diabetic nephropathy. Diabetes 60: 3055-3066, 2011.

291. Zhou G, Wang Y, He P, and Li D. Probucol inhibited Nox2 expression and attenuated podocyte injury in type 2 diabetic nephropathy of db/db mice. Biol Pharm Bull 36: 1883-1890, 2013.

292. Zhou R, Yazdi AS, Menu P, and Tschopp J. A role for mitochondria in NLRP3 inflammasome activation. Nature 469: 221-225, 2011.

293. Ziyadeh FN. Mediators of diabetic renal disease: the case for TGF- $\beta$ as the major mediator. J Am Soc Nephrol 15: S55-S57, 2004.

294. Zuo X, Tian C, Zhao N, Ren W, Meng Y, Jin X, Zhang Y, Ding $S$, Ying $C$, and Ye X. Tea polyphenols alleviate high fat and high glucose-induced endothelial hyperpermeability by attenuating ROS production via NADPH oxidase pathway. BMC Res Notes 7: 120, 2014.

Address correspondence to: Prof. Karin Jandeleit-Dahm Diabetes Complications Division JDRF Danielle Alberti Memorial Centre for Diabetic Complications

Baker IDI Heart \& Diabetes Institute PO Box 6492 St. Kilda Road Melbourne 8008 Victoria Australia

E-mail: karin.jandeleit-dahm@bakeridi.edu.au

Date of first submission to ARS Central, February 11, 2016; date of acceptance, February 21, 2016.

$\begin{aligned} & \text { Abbreviations Used } \\ & \text { 8-iso PGF2 }=8 \text {-iso prostaglandin F2 } \\ & \text { 8-OHdG }=8 \text {-oxo-7,8-dihydro-2-deoxyguanosine } \\ & \text { ACE }=\text { angiotensin-converting enzyme } \\ & \text { ADAM17 }=\text { ADAM metallopeptidase domain } 17 \\ & \text { AGE }=\text { advanced glycation end products } \\ & \text { AMPK }=5^{\prime} \text { AMP-activated protein kinase } \\ & \text { AngII }=\text { angiotensin II } \\ & \text { AOPP }=\text { advanced oxidation protein product } \\ & \mathrm{ATP}=\text { adenosine triphosphate } \\ & \mathrm{CAT}=\text { catalase } \\ & \mathrm{CCD}=\text { cortical collecting duct } \\ & \mathrm{COX} 2=\text { cyclooxygenase } 2 \\ & \mathrm{CTGF}=\text { connective tissue growth factor } \\ & \mathrm{DKD}=\text { diabetic kidney disease } \\ & \mathrm{DN}=\text { diabetic nephropathy } \\ & \mathrm{DNA}=\text { deoxyribonucleic acid } \\ & \mathrm{DPI}=\text { diphenylene iodonium } \\ & \mathrm{DuOx}=\text { dual oxidases } \\ & \mathrm{ECM}=\text { extracellular matrix } \\ & \mathrm{eGFR}=\text { estimated glomerular filtration rate }\end{aligned}$

EMT $=$ epithelial-mesenchymal transition eNOS $=$ endothelial nitric oxide synthase

ERK1/2 = extracellular signal-related kinases 1 and 2

$\mathrm{ESRD}=$ end-stage renal disease

$\mathrm{ETC}=$ electron transport chain

$\mathrm{FAD}=$ flavin adenine dinucleotide

$\mathrm{Gpx}=$ glutathione peroxidase

$\mathrm{H}_{2} \mathrm{O}_{2}=$ hydrogen peroxide

$\mathrm{HG}=$ high glucose

HRGEC = human renal glomerular endothelial cell

HUVEC $=$ human umbilical vein endothelial cell

IGF-I = insulin-like growth factor-I

IL-1 = interleukin-1

IL-6 = interleukin-6

$\mathrm{JNK}=$ c-Jun N-terminal kinase

Keap1 $=$ Kelch-like ECH-associated protein 1 $\mathrm{KO}=$ knockout

LPS = lipopolysaccharide

MAPK $=$ mitogen-activated protein kinase

$\mathrm{MCD}=$ medullary collecting duct

MCP-1 = monocyte chemotactic protein-1

mir-25 = microRNA-25

$\mathrm{MPO}=$ myeloperoxidase

mTORC1 $=$ mammalian target of rapamycin complex 1

mtROS $=$ mitochondrial ROS

$\mathrm{NADPH}=$ nicotinamide adenine dinucleotide phosphate

$\mathrm{NF}-\kappa \mathrm{B}=$ nuclear factor-kappa $\mathrm{B}$

NHE3 $=\mathrm{Na}^{+} / \mathrm{H}^{+}$exchanger isoform 3

$\mathrm{NO}=$ nitric oxide

NOS $=$ nitric oxide synthase

$\mathrm{NOX}=\mathrm{NADPH}$ oxidase

NOXA $1=$ Nox activator 1

NOXO1 $=$ Nox organizer 1

Nrf2 $=$ NFE2-related factor 2

PAI-1 = plasminogen activator inhibitor-1

$\mathrm{PKB}=$ protein kinase $\mathrm{B}$

$\mathrm{PKC}=$ protein kinase $\mathrm{C}$

PKC- $\alpha=$ protein kinase $\mathrm{C}$-alpha

PKC- $\beta=$ protein kinase C-beta

Poldip2 $=$ polymerase $($ DNA-directed $)$ delta-interacting protein 2

PUMA $=$ p53-upregulated modulator of apoptosis

RAAS $=$ renin-angiotensin-aldosterone system

Rac $=$ Ras-related C3 botulinum toxin substrate

RAGE $=$ receptor for advanced glcyation end products

$\mathrm{ROCK}=$ Rho-associated protein kinase

ROS $=$ reactive oxygen species

SGLT2 $=$ sodium glucose cotransporter 2

SOD $=$ superoxide dismutase

$\mathrm{STZ}=$ streptozotocin

$\mathrm{TAL}=$ thick ascending limb of the loop of Henle

$\mathrm{TAL}=$ thick ascending limb of the loop of Henle

TGF- $\beta=$ transforming growth factor-beta

TGF- $\beta \mathrm{R} 1=$ transforming growth factor receptor 1

TNF- $\alpha=$ tumor necrosis factor-alpha

TRPC6 $=$ transient receptor potential cation channel, subfamily $\mathrm{C}$, member 6

TxNIP $=$ thioredoxin-interacting protein

VCAM-1 = vascular cell adhesion protein-1

VEGF $=$ vascular endothelial growth factor

$\alpha$-SMA $=$ alpha-smooth muscle actin 